\title{
The Contribution of Rain Gauges in the Calibration of the IMERG Product: Results from the First Validation over Spain
}

\author{
FRANCISCO J. TAPIADOR \\ Department of Environmental Sciences, Institute of Environmental Sciences, Earth and Space Sciences Research Group, \\ University of Castilla-La Mancha, Toledo, Spain
}

\begin{abstract}
Andrés NAVArro, EduARdo García-Ortega, Andrés Merino, AND José Luis SÁnCheZ
Department of Applied Physics, Atmospheric Physics Group, University of León, León, Spain
\end{abstract}

Cecilia Marcos

Spanish Meteorological Agency (AEMET), Madrid, Spain

CHRISTIAN KUMMEROW

Department of Atmospheric Science, Colorado State University, Fort Collins, Colorado, and University of Castilla-La Mancha, Toledo, Spain

(Manuscript received 24 May 2019, in final form 2 December 2019)

\begin{abstract}
After 5 years in orbit, the Global Precipitation Measurement (GPM) mission has produced enough qualitycontrolled data to allow the first validation of their precipitation estimates over Spain. High-quality gauge data from the meteorological network of the Spanish Meteorological Agency (AEMET) are used here to validate Integrated Multisatellite Retrievals for GPM (IMERG) level 3 estimates of surface precipitation. While aggregated values compare notably well, some differences are found in specific locations. The research investigates the sources of these discrepancies, which are found to be primarily related to the underestimation of orographic precipitation in the IMERG satellite products, as well as to the number of available gauges in the GPCC gauges used for calibrating IMERG. It is shown that IMERG provides suboptimal performance in poorly instrumented areas but that the estimate improves greatly when at least one rain gauge is available for the calibration process. A main, generally applicable conclusion from this research is that the IMERG satellite-derived estimates of precipitation are more useful $\left(r^{2}>0.80\right)$ for hydrology than interpolated fields of rain gauge measurements when at least one gauge is available for calibrating the satellite product. If no rain gauges were used, the results are still useful but with decreased mean performance $\left(r^{2} \approx 0.65\right)$. Such figures, however, are greatly improved if no coastal areas are included in the comparison. Removing them is a minor issue in terms of hydrologic impacts, as most rivers in Spain have their sources far from the coast.
\end{abstract}

\section{Introduction}

Precise estimation of precipitation is crucial for semiarid areas, especially in a context of ongoing global warming (UNCCD 2017). In these areas, every drop counts and expected changes in the cycles of precipitation can exert major stress on biota and greatly affect human activities (Tapiador et al. 2016). Knowledge of how much precipitation is available in a particular location is

Corresponding author: Francisco J. Tapiador, francisco.tapiador@ uclm.es important to validate climate models and adjust and tune their parameters (Hourdin et al. 2017), while timely estimates of precipitation are a must for hydrologic operations (Brunetti et al. 2018; Maggioni et al. 2013; Tian et al. 2007).

There is little need to justify the use of satellites for measuring precipitation in many of the world's data scarce regions, especially oceans (Kidd et al. 2017). There is a useful role for satellite estimates, however, even over reasonably well-gauged regions. By providing a homogeneous view of the entire area, their products are not as susceptible to changes in precipitation inferred by 


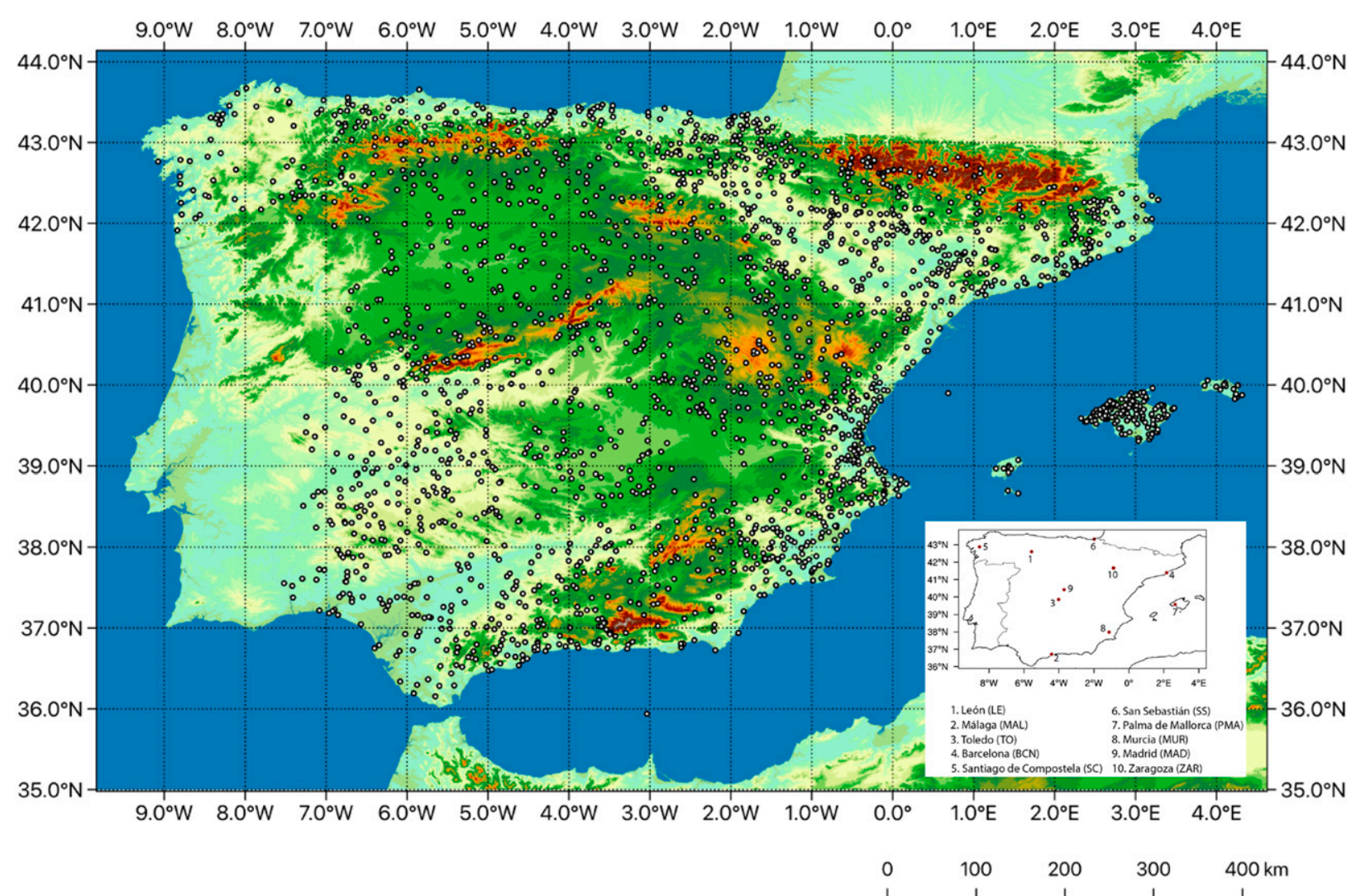

FIG. 1. Topographical map of the Iberian Peninsula as derived from the Shuttle Radar Topography Mission (SRTM) data (30-m resolution), including the spatial distribution of the official first-order, high-quality rain gauge stations of Spain. Color scale as in Fig. 13 below. The inset map in the bottom-right corner provides the key for identifying some cities in the following figures.

ground-based systems when the observing system changes (a nearly continuous condition with rain gauge networks), quality control procedures for individual rain gauges, location issues (most gauges are in valleys rather than mountains tops or hillsides) and the many other issues that have arisen in the last decades regarding gauges (Habib et al. 2008; Nešpor and Sevruk 1999; Upton and Rahimi 2003; Villarini et al. 2008). Moreover, satellites can provide faster data than quality-controlled rain gauge networks that may have significant delays due to data collection and quality control procedures.

To fully benefit from these satellite data, it is instructive to assess how well a global product (IMERG in this case) validates against the best rain gauge network that is available in Spain. While the Iberian Peninsula (hereafter IP) is covered by meteorological radars (Gutiérrez and Aguado 2006; Marcos et al. 2015), there is currently no merged radar/rain gauge quantitative precipitation estimate (QPE) that covers the entire domain. This leads to some open question in Spain's mountainous regions. The high spatial variability of precipitation and the distances between first-order stations (Fig. 1) can result in large areas of the territory relying on suboptimal environmental information.

The Global Precipitation Measurement (GPM) mission (Hou et al. 2014; Skofronick-Jackson et al. 2017a,b, 2018a,b) forms the basis of global retrievals of precipitation at spatial and temporal scales suitable for hydrologic applications in Spain. Since the GPM Core Observatory was launched in 2014, a number of studies focusing on regional rainfall performance have been conducted. These have focused on Italy (Petracca et al. 2018), Austria (Sungmin et al. 2017), the Alps (Gabella et al. 2017), China (Tian et al. 2018), the British Isles (Watters et al. 2018), Cyprus (Retalis et al. 2018), the Amazon (Oliveira et al. 2018), and the tropical Andes (Manz et al. 2017). The present paper aims to not only add to such undertaking over Spain, but to examine the underlying reasons for agreements and discrepancies while using standard validation metrics appropriate for hydrological applications, similar to Tan et al. (2016) but from a different perspective.

This paper is organized as follows: section 2 will describe data sources. In section 3 a comparison will be 
presented through seven subsections that analyze all IMERG products at different temporal scales. The discussion and conclusions are presented in sections 4 and 5 , respectively.

\section{Study area and data}

\section{a. Study area}

In most of Spain, rainfall is scarce, and this has profoundly affected the landscape, agriculture, industry, and way of life. Droughts recurrently affect the country and are the key limiting factor in Spain's natural and agricultural development. Dams and reservoirs mitigate their effects, but only in a limited way. The only area in Spain with no dry month is the far north. Most of the plateau and the two main depressions have 3-5 dry months. This is a serious problem due to the potential changes resulting from global warming, as much of the country is at the very limit of receiving a reasonable amount of rainfall to sustain life throughout the long, dry, and hot summer. Indeed, expected changes in rainfall and snow cycles could have a highly negative impact in such semiarid country. Careful hydrological planning based on the best available information is critical for the country's future sustainability.

The relief of Spain can be described characterized by the central plain or mesa (La Meseta), the several main mountain ranges, and the two depressions (Ebro River in the east and Gualdalquivir River in the southwest). Thus, there are eight major orographic systems in continental Spain. The most important mountain systems are the Cantabrian System (northwest), the Pyrenees (northeast), the Central System, and the Baetic System in the southeast. The Duero Mountains and the Teruel Mountains in the east complete the picture (Tapiador 2019).

Orography and distance from the ocean play the main role modulating the climate of Spain. Based on the Köppen climate classification system (Köppen 1900), most of the territory has Mediterranean climates (Csa and $\mathrm{Csb}$ ), except the north (which experiences oceanic climates $\mathrm{Cfa}$ and $\mathrm{Cfb}$ ), the southeast (which is defined by semiarid and arid climates BSk, BSh and BWh), and the mountainous areas of northern Spain (Dfc and Dsc).

Accurate precipitation is critical in Spain because of its reliance on built infrastructure to satisfy the country's water needs. A major challenge for the country is to deal with a large latitudinal gradient in precipitation: there is a humid country $\left(>500 \mathrm{~mm} \mathrm{yr}^{-1}\right)$ in the north and a dry country in the south. The rainiest areas $\left(>1500 \mathrm{~mm} \mathrm{yr}^{-1}\right)$ of the Iberian Peninsula are the northwest and north, due to the influence of the Cantabrian System. In the east, precipitation is more irregular than in the west, due to the influence of convective storms, especially in summer (Merino et al. 2013; García-Ortega et al. 2017). A way to achieve territorial balance in water availability has been an open question in the country for the last century.

\section{b. Data}

Coincident and quality-controlled data for the period from March 2014 to May 2017 were used. The following subsections briefly describe the gauge data (AEMET, GPCC), gauge-adjusted satellite (GPCP), TMPA, and reanalysis (ERA5) data, and the GPM products to be validated (IMERG).

\section{1) AEMET DATA}

The Spanish Meteorological Agency (AEMET) produces a high-resolution gridded $(5 \mathrm{~km} \times 5 \mathrm{~km})$ precipitation product as a part of its climatological analyses. The dataset is based on daily accumulated precipitation records of $\sim 2300$ gauges, covering the Iberian Peninsula and the Balearic Islands (Fig. 1). The product spans the 1951-2017 period.

AEMET uses the optimal interpolation method (Gandin 1965) to generate the precipitation estimates. Quality control (QC) includes several checking algorithms such as first guess (FG) and direct comparison with neighboring stations. After the first QC, gridded data are further validated against 64 independent weather stations (see Peral et al. 2017 for details).

The gridded daily precipitation data were upscaled to $10 \mathrm{~km}$ using a first-order conservative remapping method (Jones 1999). The purpose of conservative remapping is to bring observations and IMERG on the same grid while preserving the statistical properties of the original precipitation field.

\section{2) GPCC DATA}

The Global Precipitation Climatology Centre (GPCC; Schneider et al. 2017) provides global precipitation analyses for monitoring and research of Earth's water cycle. Their database contains precipitation data of more than $\sim 80000$ rain gauges (115 rain gauges over the IP). Different gridded precipitation products based on this data are released on a regular basis. One of these products is the GPCC Monitoring Product version 6 (GPCC-MP; Schneider et al. 2018). It provides monthly precipitation data at $1.0^{\circ} \times 1.0^{\circ}$ in near-real time.

\section{3) GPCP DATA}

The Global Precipitation Climatology Project (GPCP) was developed by the World Climate Research Programme (WCRP) to quantify the global distribution of precipitation. GPCP merges several satellite-based estimates with precipitation gauge analyses over land from the GPCC. This combination of stations and satellite measurements 
enhances the quality of final precipitation estimates (Adler et al. 2018).

The GPCP one-degree daily (1DD) precipitation analysis (Huffman et al. 2001) is a climate data record (CDR) available from October 1996 onward. It uses a threshold-matched precipitation index (TMPI) to produce instantaneous precipitation using geo-IR observations. Specifically, a regionally varying IR threshold is matched against the fractional coverage of the SSM/Iand SSMIS-derived GPROF precipitation estimates. The rain rate of the IR pixel is then computed so that the TMPI monthly precipitation equals that of the corresponding satellite-gauge monthly precipitation total. Outside $40^{\circ} \mathrm{N}-40^{\circ} \mathrm{S}$, precipitation estimates from the TOVS and AIRS sensors are adjusted by the precipitation occurrence of GPROF at $40^{\circ}$ latitude (Tapiador et al. 2017).

\section{4) IMERG ESTIMATES}

The IMERG product intercalibrates, merges, and interpolates all available satellite passive microwave precipitation estimates with microwave-calibrated infrared (IR) satellite estimates to produce a satellite-only product. This product is then further bias adjusted to fit rain gauge data, where available, and further merged with this data to produce a final product at $10-\mathrm{km}, 30$-min resolution globally. A complete description of the algorithm and data can be found in Huffman et al. (2018, 2019).

Three IMERG v05B level 3 estimates of precipitation were used in this paper: the early release product (IMERG-E), the late product (IMERG-L), and the final product (IMERG-F), which is the one that can be deemed as the base for building climatologies of precipitation for hydrological purposes.

The early (IMERG-E) and late run (IMERG-L) are conceptually the same but differ in their latency and in how the IR data is folded into the microwave estimate. IMERG-E is designed for applications that require data as early as possible and is available no later than $4 \mathrm{~h}$ after the event, while IMERG-L postpones the processing to wait for additional satellite data that may be delayed for any number of reasons. The early version also uses only forward propagation of the microwave precipitation estimate using IR data (which basically amounts to extrapolation), while the late has both forward and backward propagation (allowing interpolation). IMERG-L is available $15 \mathrm{~h}$ after the event. Both products use a climatological adjustment to GPCC rain gauges that uses prior years to compute mean offsets between monthly gauge products and the satellite-only estimates. The gauge adjustment is fairly broad to minimize the introduction of small-scale features that are only in the gauge data and not present in the satellite estimates. Satellite data that are delayed even further can be incorporated into the final run (IMERG-F).

The IMERG-F product incorporates the actual rain gauge estimates from the Global Precipitation Climatology Centre based upon the relative uncertainty of the satellite and gauge data. Uncertainties vary with the number of satellite microwave observations available. However, the major change in the uncertainty comes from the number of GPCC gauges available within a $1^{\circ}$ grid, as the number of satellite microwave sensors changes relatively little over time. The gauge data, being coarser in both space and time than the IMERG product, are merged at the monthly time scale to derive an overall scale factor which is then applied to each 30-min, 10-km IMERG pixel.

\section{5) TMPA ESTIMATES}

The Tropical Rainfall Measuring Mission (TRMM) Multisatellite Precipitation Analysis (TMPA; Huffman et al. 2007) provides a calibration-based sequential scheme for combining precipitation estimates from multiple satellites, as well as gauge analyses where feasible, at fine scales $\left(0.25^{\circ} \times 0.25^{\circ}\right.$ and 3 hourly $)$. TMPA was available both after and in real time, based on calibration by the TRMM Combined Instrument and TRMM Microwave Imager precipitation products, respectively. The dataset covers the latitude band $50^{\circ} \mathrm{N}-50^{\circ} \mathrm{S}$ for the period from 1998 to December 2019.

\section{6) ERA5 REANALYSIS}

ERA5 reanalysis (Hersbach et al. 2019) was used in order to compare IMERG estimates with a model-based precipitation climatology. Reanalyses are widely considered as the best, physically consistent estimate of the atmospheric state and include observations through data assimilation. It is included here as modern, high-resolution models are beginning to perform on par with satellite precipitation observations, particularly in situations of largescale ascent or orographic forcing (Currier et al. 2017).

\section{Comparisons}

First, GPCC and GPCP 1DD data were compared with the IMERG and the TMPA. The spatial resolution of both datasets is clearly too coarse to allow detailed hydrological applications in Spain (Fig. 2). Even though the GPCC correctly captures the areas with more precipitation in the north, the GPCP estimate falls short of expectations and does not provide a reasonable picture of the annual mean precipitation of the country over the period. It does not even seem to capture the general GPCC gauge climatology that it is tuned to-albeit not on the individual grid box scale. It is included here simply to illustrate this point. 
A

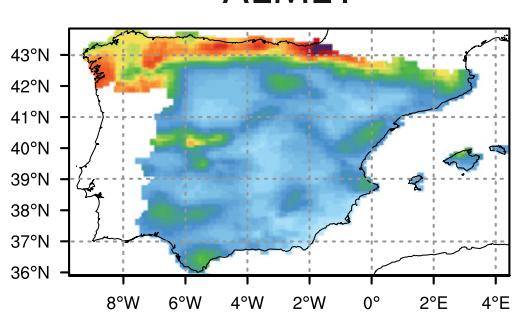

GPCC

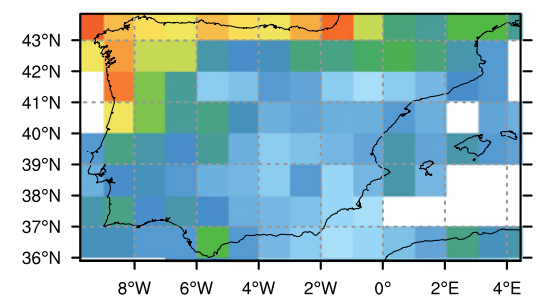

IMERG

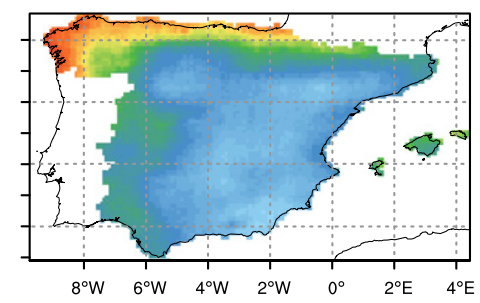

TMPA

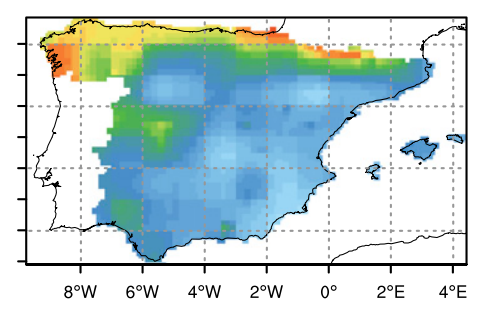

B
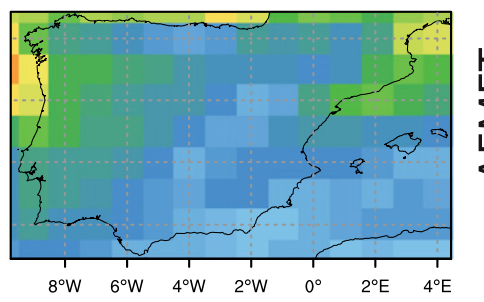

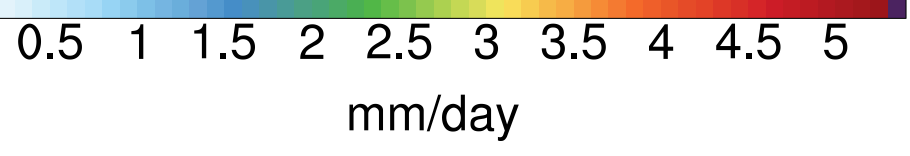

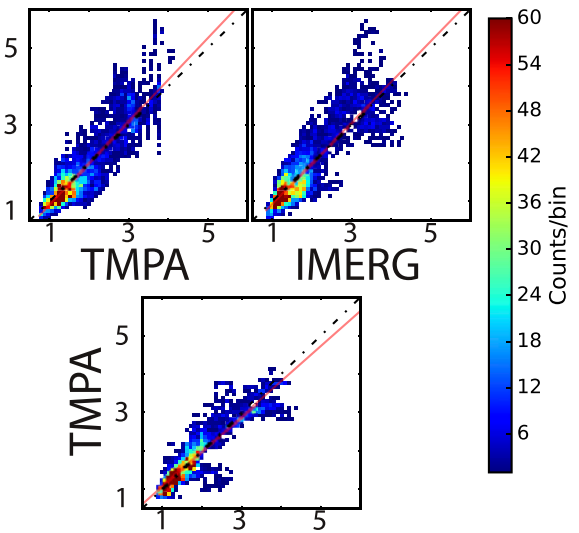

IMERG

FIG. 2. (a) Comparison of the annual mean precipitation of the period (March 2014-May 2017) as in the (top left) AEMET, (top middle) IMERG-F, (top right) TMPA, (bottom left) GPCC, and (bottom right) GPCP datasets. The spatial resolution of the first two panels is $0.1^{\circ}$, whereas GPCP and GPCC are mapped at $1^{\circ}$ resolution. (b) Scatterplots for TMPA vs AEMET, IMERG vs AEMET, and IMERG vs TMPA.

The GPCC uses some of the official rain gauges of the AEMET, but these are processed differently and aggregated at $1^{\circ}$. Nonetheless, the GPCC differs substantially only in the Sierra de Gredos mountain range, in the latitude-longitude box $\left(41^{\circ} \mathrm{N}, 6^{\circ} \mathrm{W}\right),\left(40^{\circ} \mathrm{N}, 5^{\circ} \mathrm{W}\right)$ where AEMET data show a local maximum that is blurred (or missed) by GPCC. Such a particular location is challenging for any low-resolution scheme given the sharp gradients, the high altitude, and the complex orography (cf. Fig. 2). This example shows an instance where precision and spatial resolution are critical for hydrometeorology since that mountain range provides the water for the dams in the south.

Figure 3 complements the previous comments showing the effect of upscaling AEMET data to the GPCC spatial resolution. The annual mean (top) presents a good overall agreement, but some points are notoriously skewed such as $\left(43^{\circ}-44^{\circ} \mathrm{N}, 1^{\circ}-2^{\circ} \mathrm{W}\right),\left(36^{\circ}-37^{\circ} \mathrm{N}, 5^{\circ}-6^{\circ} \mathrm{W}\right)$, and $\left(41^{\circ}-42^{\circ} \mathrm{N}, 7^{\circ}-8^{\circ} \mathrm{W}\right)$. The seasonal plots distribute the mismatches across all seasons, so it is systematic bias and not the results of specific events. Figure 3 also shows that the rain gauge information used to adjust IMERG (GPCC) is indeed not exactly the same that the one used for validation (otherwise they will be identical). As mentioned above, the reason is dissimilar processing methods and filtering procedures on an otherwise presumably slightly different choice of stations. A potential source of discrepancy is also that AEMET delivers the gauge data from 0700 to 0659 UTC and GPCC provides their amalgamation from 0000 to 2359 UTC. Upscaled IMERG-F compares well with both observational datasets, even seasonally.

\section{a. Annual, 4-yr mean}

Standard comparisons for the annual and seasonal "climatologies" were performed against AEMET data as the reference. Figure 4 shows the three annual climatologies as derived by the $\mathrm{E}, \mathrm{L}$, and $\mathrm{F}$ versions of IMERG.

Quite evident is the fact that all IMERG products are similar. This is not surprising since the climatological gauge adjustment is expected to work well over long time scales while specific issues related to missing or capturing individual storm systems should create only random differences. All IMERG products capture the general pattern of precipitation fairly well, but some specific discrepancies are worth pointing out. First, differences in precipitation values are observed both in the 
AEMET

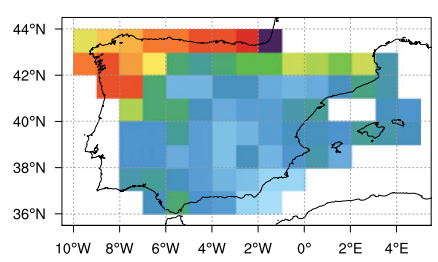

GPCC

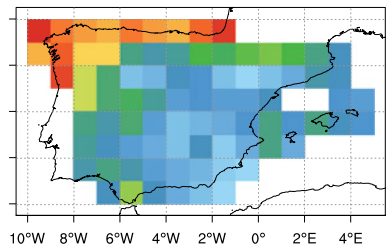

0.511 .522 .533 .544 .5

$\mathrm{mm} / \mathrm{day}$
IMERG-F

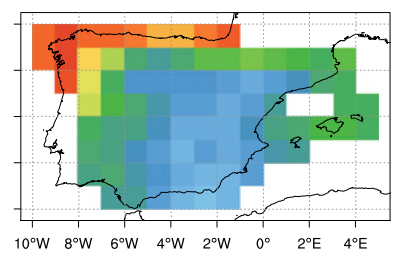

AEMET
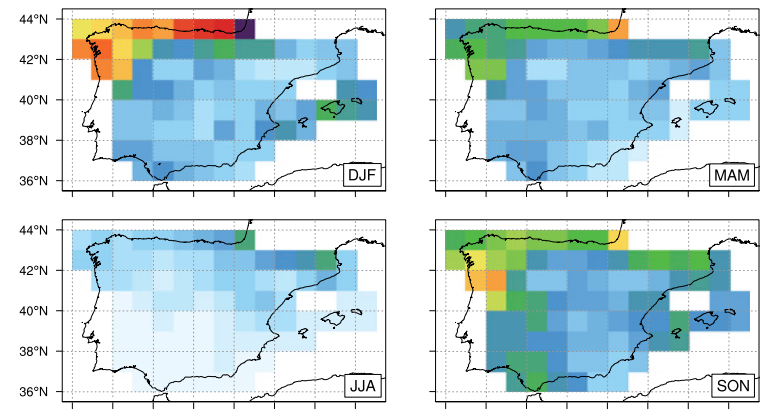

GPCC
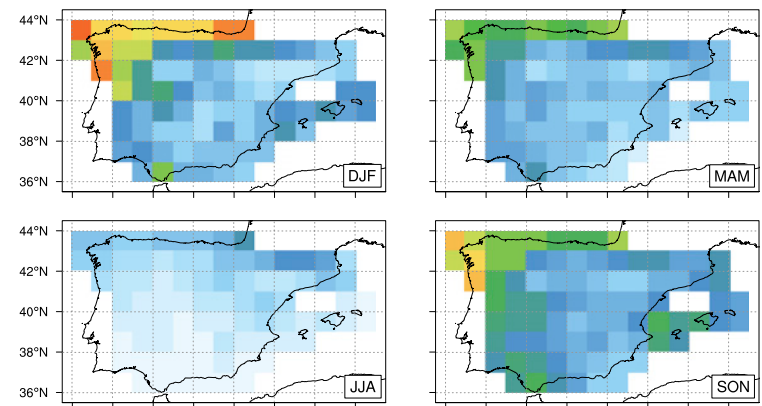

IMERG-F
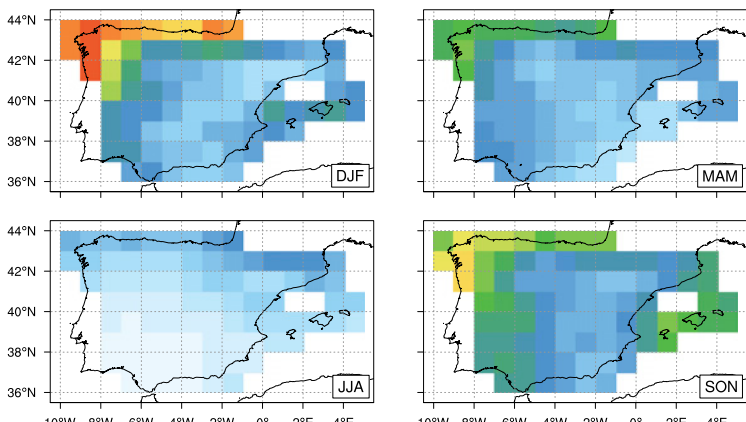

\begin{tabular}{llll}
\hline & 1 & 2 & 3 \\
$\mathrm{~mm} / \mathrm{d} a y$ & 5
\end{tabular}

FIG. 3. Comparison at the same spatial resolution of the (top) annual and (bottom) seasonal mean precipitation for AEMET, GPCC, and IMERG-F, for the March 2014-May 2017 period. AEMET and IMERG-F have been upscaled here to the GPCC resolution. The upscaling was performed using the conservative remapping method. 

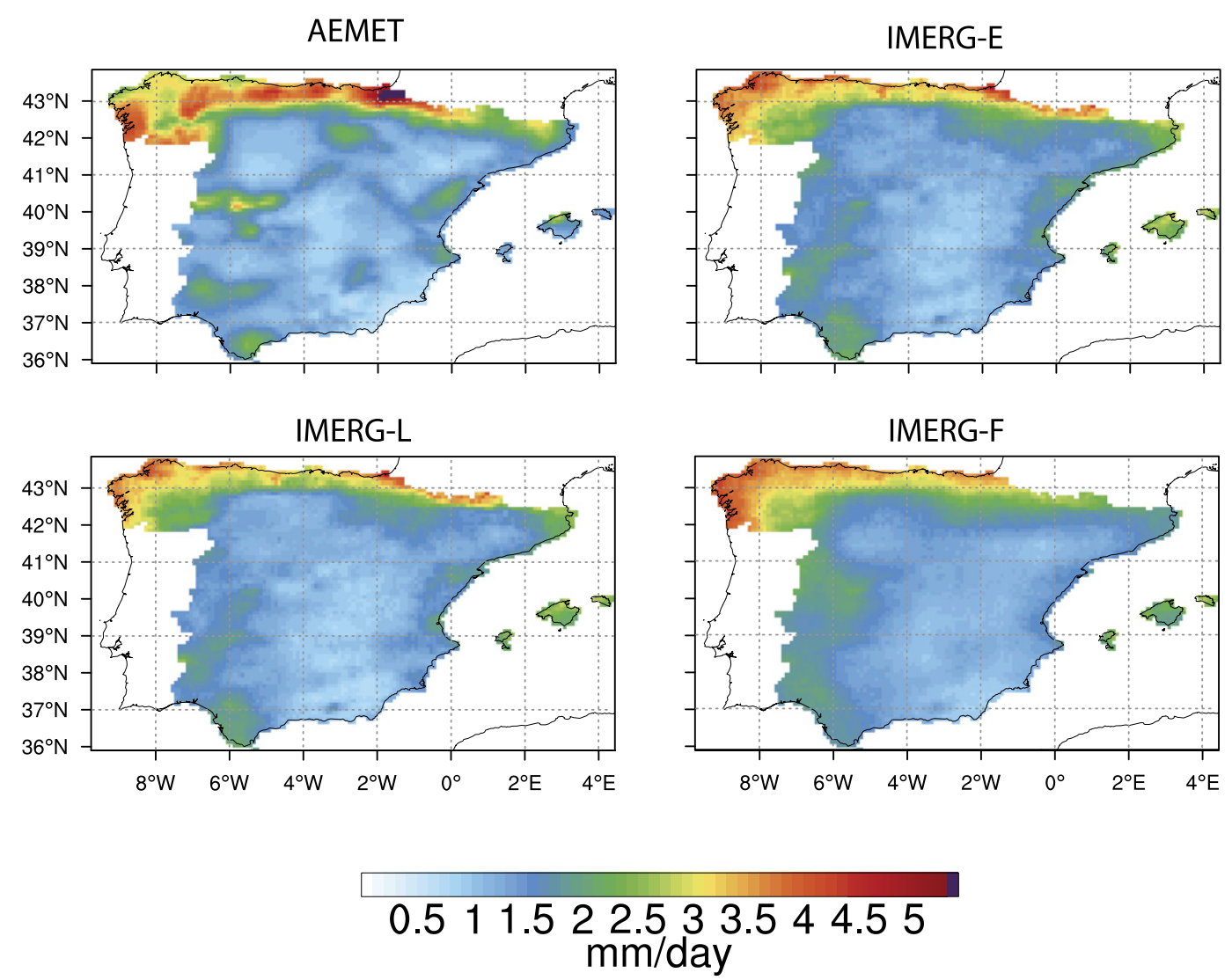

FIG. 4. A comparison of the annual mean precipitation for AEMET and three IMERG products for the March 2014-May 2017 period.

Cantabrian Mountains at the north of the IP, as well as in the northern and northwestern coasts.

The poorest results are shown in the IMERG-E and IMERG-L products, whereas IMERG-F shows slightly more accurate precipitation in these areas. Moreover, the maximum values of precipitation in the Sierra de Gredos $\left(40^{\circ}-41^{\circ} \mathrm{N} ; 5^{\circ}-7^{\circ} \mathrm{W}\right)$ are not visible in the IMERG-E and $-\mathrm{L}$ products, while the pattern is discernable, but highly smoothed by IMERG-F. The maximum precipitation areas in northern Spain, corresponding to convective rain related to mesoscale factors and orographic forcings, are not well captured by any of the IMERG products. This is likely a result of the smoothing filter applied by IMERG to avoid high-resolution fluctuations not explicitly contained in the satellite data.

\section{b. Seasonal comparisons}

The seasonal plots (Fig. 5) show many of the same features discussed in the annual averages. In general, in summer months, the precipitation in the IP is low and scarce, but what little convection exists in the northeast appears smoothed, especially in IMERG-F relative to IMERG-E and IMERG-L. This is likely a visual effect in that the overall precipitation is closer much to the gauge analysis than IMERG-E and IMERG-L, and thus does not offer the contrast shown in the IMERG-E and IMERG-L products that appears to capture the regions of higher precipitation-albeit showing significant overestimates.

It is also noticeable that the Gredos Range appears quite similar in all three products in the fall (SON), but does not appear in the annual means for IMERG-E and IMERG-L shown in Fig. 4. This can be ascribed to an underestimation of precipitation in this region during the other seasons. Generally, IMERG-E and IMERG-L (Figs. 6 and 7) overestimate seasonal precipitation in summer but underestimate the precipitation in mountainous areas, as in Cantabrian, Gredos, or Iberian Ranges the rest of the year (Figs. 6-8).

\section{c. IMERG versions comparisons with AEMET data: Annual estimates}

Figure 9 shows the difference in the annual mean precipitation for AEMET and the three IMERG products. There are discrepancies in the correlations with the gauge data (cf. scatterplots comparing the annual mean precipitation at every grid point with AEMET's estimates), but 

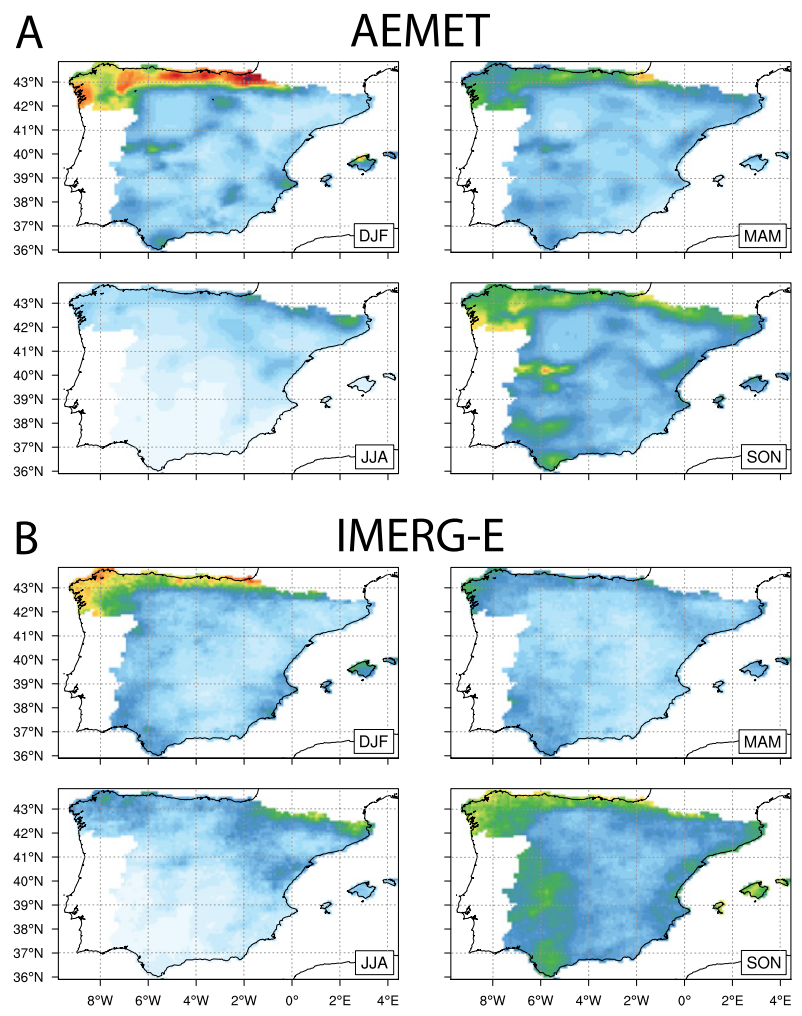
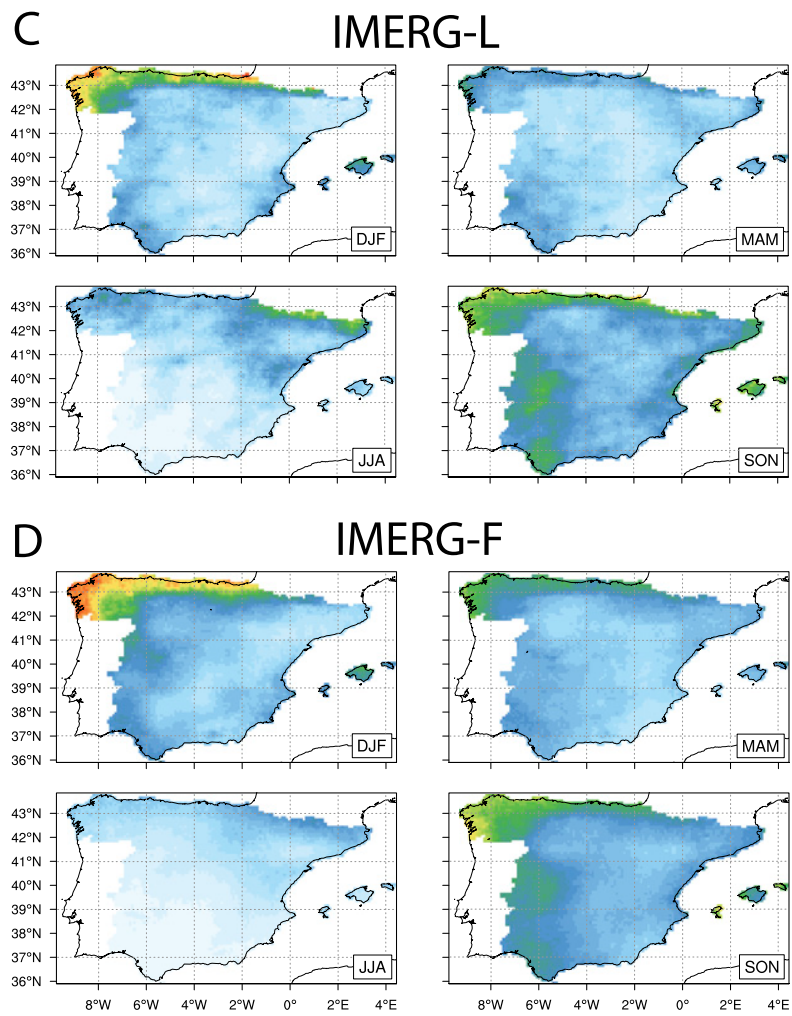

IMERG-F

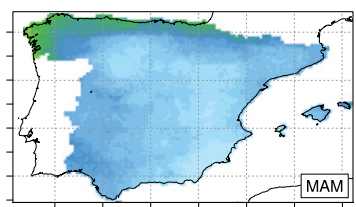

\section{$\begin{array}{lllllllll}0 & 1 & 2 & 3 & 4 & 5 & 6 & 7 & 8\end{array}$ $\mathrm{mm} /$ day}

FIG. 5. Seasonal precipitation maps for (a) AEMET, (b) IMERG-E, (c) IMERG-L, and (d) IMERG-F datasets for the March 2014-May 2017 period.

the maps show that the differences features are highly consistent among products. The differences, therefore, arise from discrepancies in the tuning procedures, and not to some fundamental physical reasons that depend upon the meteorology of specific locations.

\section{d. Histograms}

Figure 10 compares the distribution of the PDFs between observations and IMERG products. In terms of the annual mean, the distribution of the precipitation provided by IMERG is similar to that of the gauge observations (Fig. 10, top).

Seasonal variability is also well captured by IMERG. All products correctly identify the rainiest (SON) and driest seasons (JJA) but only IMERG-F correctly represents the distribution. However, IMERG-L and IMERG-E provide a more realistic distribution of precipitation in winter (DJF). IMERG-F gets better results in spring (MAM) although all IMERG versions have problems at the lower end of the distribution. Indeed, a common issue affecting all IMERG products is the underestimation of the precipitation maximum (Fig. 10 all rows except JJA). This problem clearly features in IMERG-F and is due to the smoothing effect in the GPCC rain gauges interpolation (see Fig. 3).

\section{e. Time series}

The time evolution of precipitation is critical for many applications. Figure 11 shows that IMERG-F correctly replicates the time series of observations at 10 selected cities in Spain. This test can be considered more robust than the areal comparisons since here the spatial structure of precipitation does not affect the comparison. As long as the satellite footprint is close to the area for which the observation is supposed to represent, there is a oneto-one fair correspondence between the satellite estimate and the observation. Figure 11, however, also shows some regional differences: while IMERG matches almost perfectly the series of Malaga (MAL) and Santiago de Compostela (SC), there are differences in San Sebastián (SS) and Zaragoza (ZAR).

The differences between the three IMERG versions are apparent. While the early version sometimes 
A
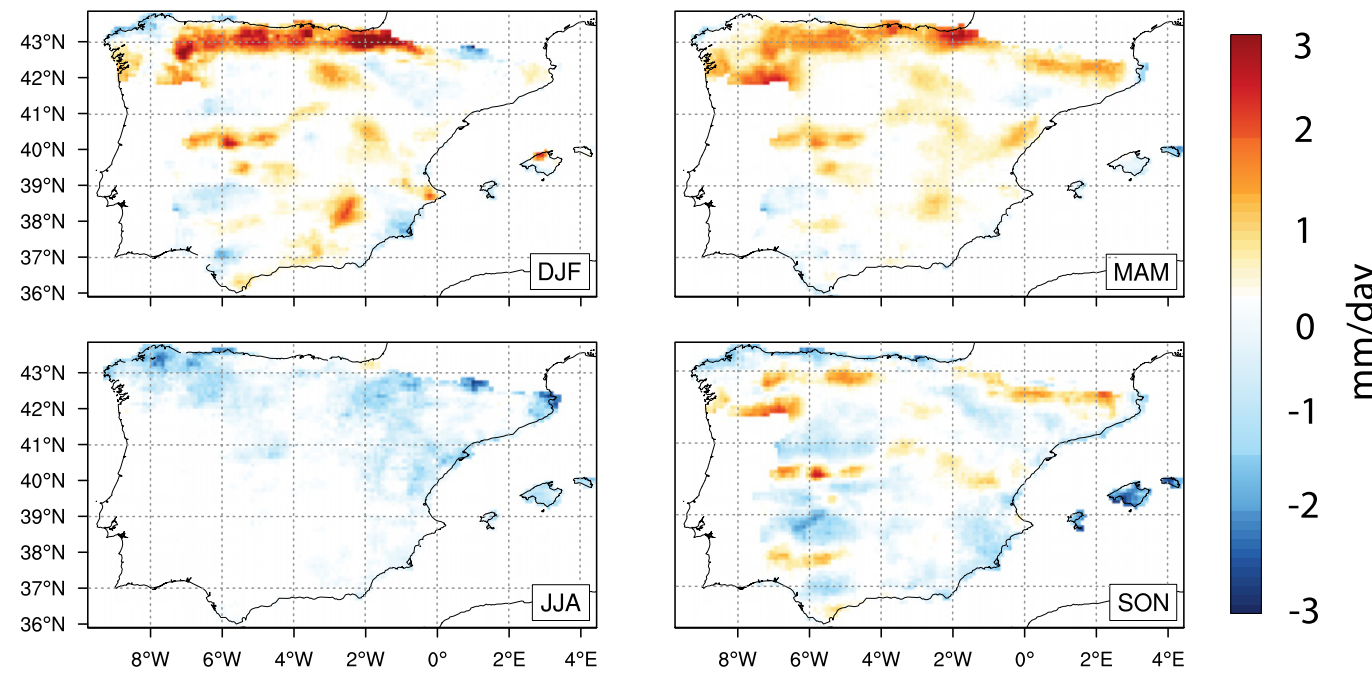

B
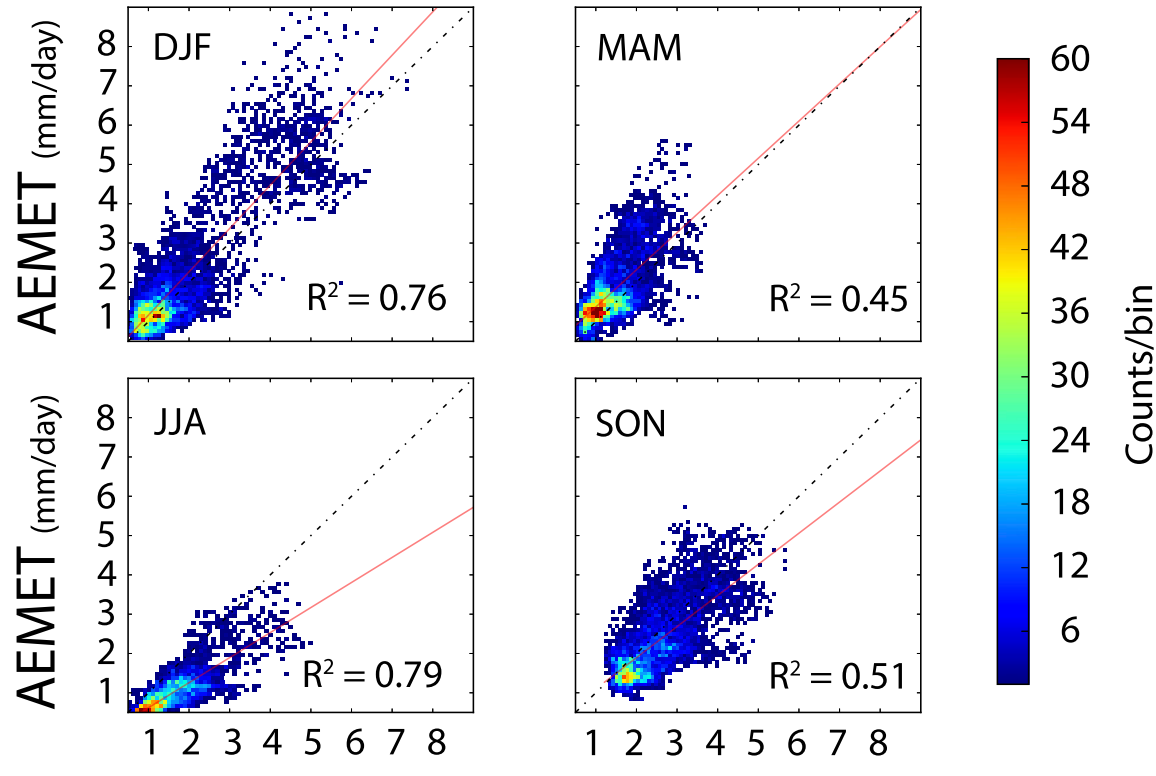

IMERG-E (mm/day)

\section{IMERG-E (mm/day)}

FIG. 6. (a) Difference maps between AEMET and IMERG-E seasonal estimates. (b) Scatterplots comparing the seasonal precipitation at every grid point.

markedly departs from the observations, and the late version sometimes does not get closer, the final version can be considered a good proxy. This is hardly surprising as the final version is gauge adjusted instead of merely corrected by climatological biases. It is also instructive to look at the differences such as in Palma de Mallorca (PMA). The discrepancies here may be due to the use of a different station (airport versus city) as it seems there is a systematic bias with satellites overestimating most of the time, and some particular times largely departing from observations. The case of Madrid is paradigmatic of good performances.

\section{f. Spatial structure of precipitation}

While there is little doubt that IMERG-F may closely follow the evolution of precipitation in those places where observations are available for calibration such as major cities (Fig. 11), satellite information is most useful where no other data are available. The success of producing realistic areal estimates of precipitation depends 

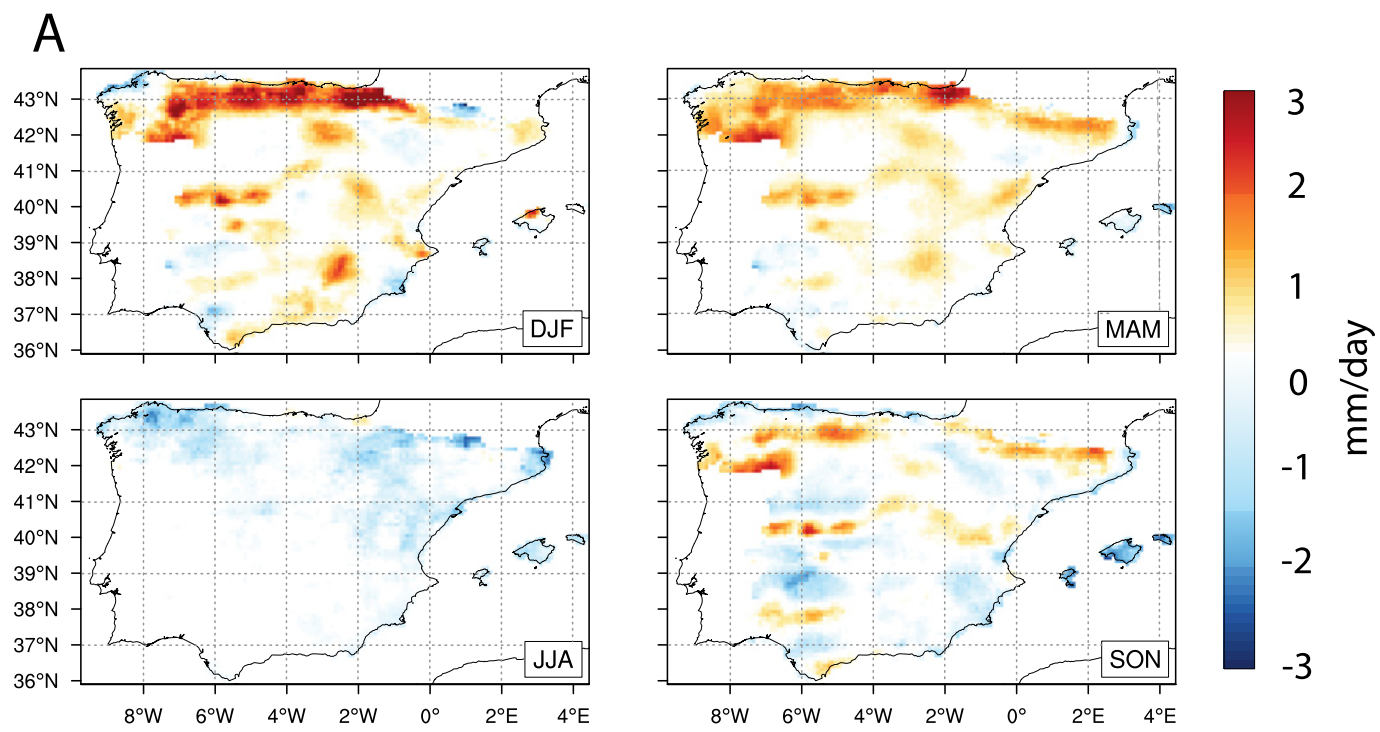

B
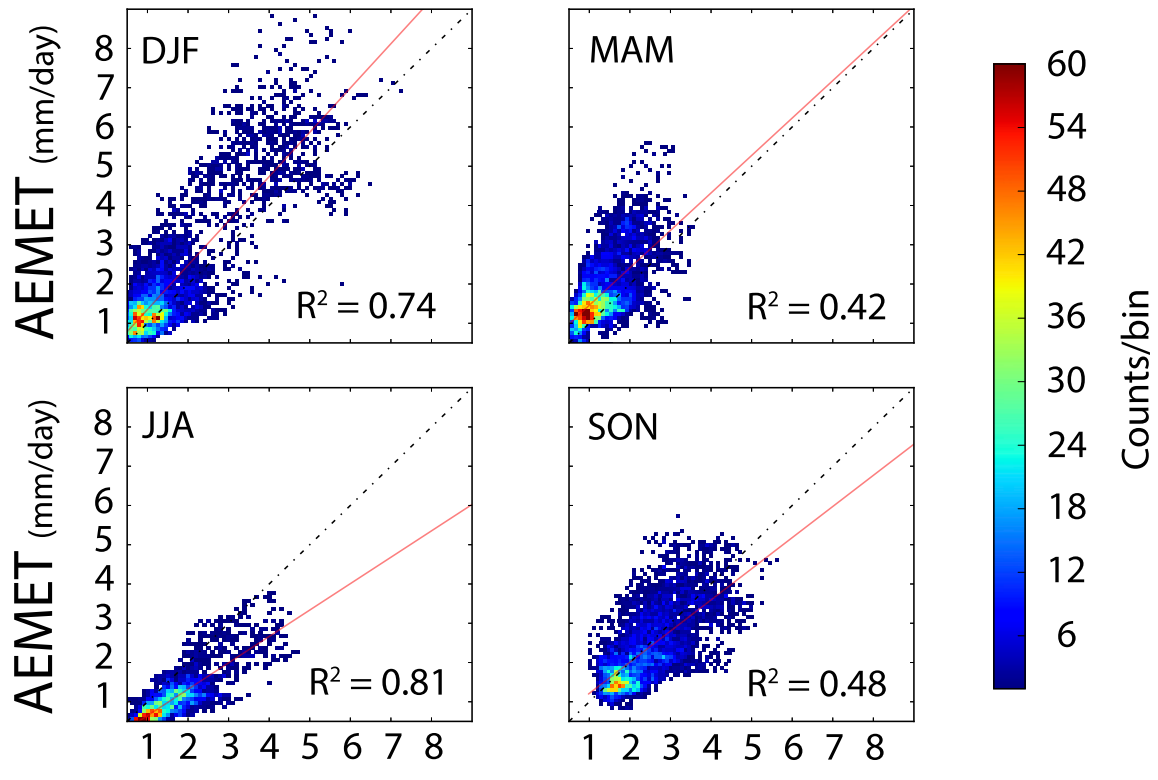

IMERG-L (mm/day)

IMERG-L (mm/day)

FIG. 7. As in Fig. 6, but for IMERG-L.

on the spatial autocorrelation of the variable. In the limiting case of no spatial correlation, interpolation is of no use. Precipitation is notoriously variable from point to point (far more than for instance temperature or even humidity), so it not trivial to infer the actual value of the variable a few kilometers from a point measurement.

To estimate the differences in the spatial structure of precipitation, the variograms of the precipitation fields from the gauges and from the satellite estimates were calculated. The use of this metric to compare precipitation fields dates back to Germann and Joss (2001). Figure 12 shows that the spatial structures of fields of the annual means are quite different. The AEMET estimate quickly decorrelates and has sharper gradients, something that is apparent in Fig. 3. The longer correlation lengths in all versions of IMERG are likely due to the averaging lengths used in both the climatological as well as the actual gauge adjustment. Interestingly, the IMERG-E is closer to that structure than IMERG-L and IMERG-F, but this may simply be a coincidence as the improved performance is not sustained across the seasons.

A seasonal breakdown of the results (Fig. 12) reveals that there are noticeable differences depending on the amount of precipitation. Except for spring (MAM), 

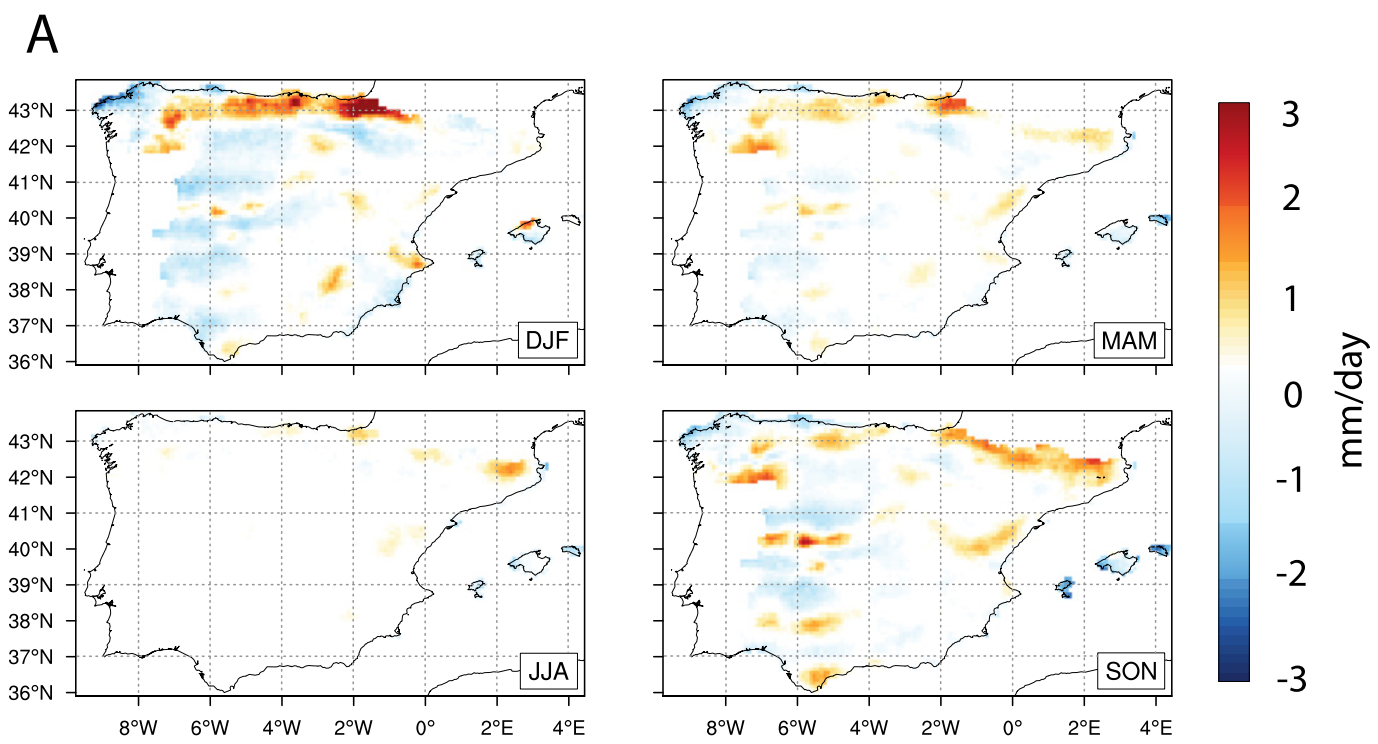

B
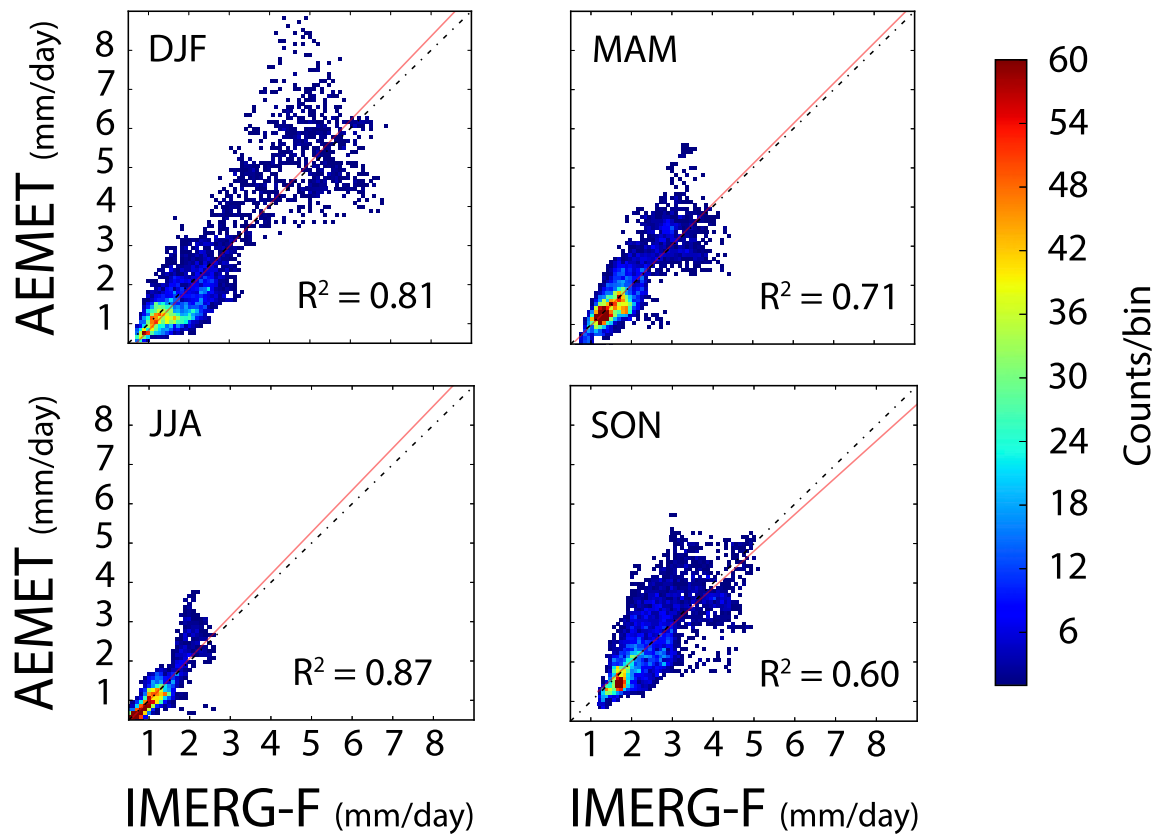

IMERG-F (mm/day)

\section{IMERG-F (mm/day)}

FIG. 8. As in Fig. 6, but for IMERG-F.

IMERG-F varies more slowly implying that the satelliteonly precipitation and the simple climatological bias correction preserves more satellite structure than the actual gauge adjustment carried out in IMERG-F. The impact of the difference in the gauge adjustment is clearly evident when comparing IMERG-F to IMERG-E and IMERG-L across the seasons.

\section{g. Threshold analysis}

Table 1 shows the root-mean-square error (RMSE) and mean absolute percentage error (MAPE) for 10 cities representative of the major climates of Spain. The metrics were computed for the three IMERG versions and four rainfall categories of daily accumulated amounts as defined following by Gallego et al. (2006).

The differences between the three IMERG versions are evident. IMERG-F presents the best performance for all rainfall categories. Late and early versions are alike, being slightly worse the early. All IMERG versions have larger MAPE for light rainfall, with decreasing the error as the rainfall intensity increases. This suggests that the IMERG has better skill in estimating 

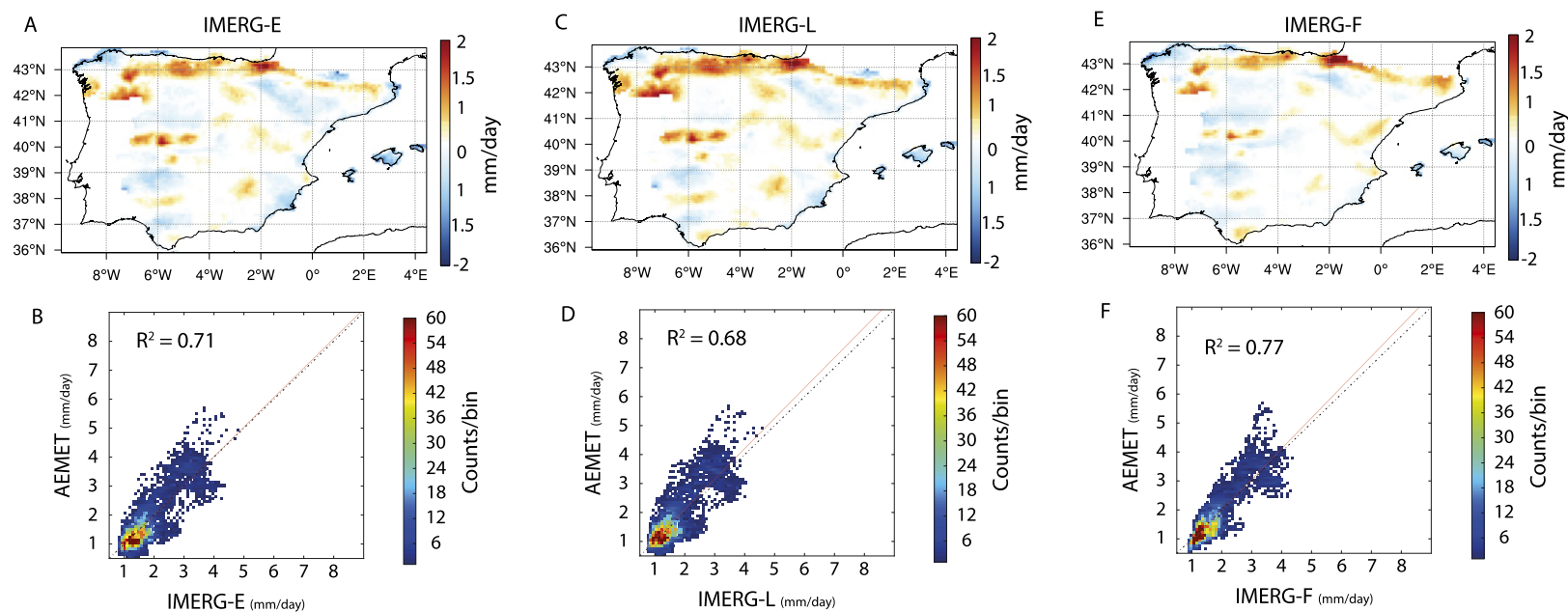

FIG. 9. (a),(c),(e) Difference of annual mean precipitation (March 2014-May 2017) for AEMET and the three IMERG products.

(b),(d),(f) Scatterplots comparing annual mean precipitation at every grid point for AEMET and the three IMERG versions.

heavy precipitation than weak precipitation. One reason for that could be that the inclusion of IR data helps identifying heavy rainfall. Another complementary reason could be the challenges in estimating weak precipitation from MW sensors.

While IMERG matches almost perfectly the monthly precipitation series, daily measurements have remarkable poor scores. Because all gauge adjustments work on monthly time scales, this implies that there is significant averaging of instantaneous estimation errors by IMERG. The mean daily MAPE for light and moderate rainfall is larger than $100 \%$.

The dissimilar performances of the IMERG are also apparent in terms of geography. In general, the products perform better in the interior than in coastal areas. Aside from algorithm issues that are always exacerbated by coastal locations, another likely cause is that coastal areas in the Mediterranean are frequency affected by heavy precipitation events due to cutoff lows. For these regions the results are affected by a small number of events with high rainfall rates, which means that misrepresenting even a single event can result in a poor monthly or annual score.

\section{Discussion}

While there are many automatic stations and secondand third-order rain gauges, first-order rain gauges capable of providing quality-controlled, good quality data are sparse in Spain. Convenience and practical requirements also result in mountain areas being poorly represented (cf. Figs. 1 and 13). But most rivers in Spain receive water from precisely such uninstrumented areas, resulting in large uncertainties for hydrologic research.
Data from the GPM constellation, and specifically the IMERG product, can capture precipitation features between gauges. These are important to adapt to the variability of the phenomena and for operations related to regional water availability. It has to be borne in mind that precipitation in semiarid areas such as eastern Spain is often a local phenomenon. The maxima that make up a large share of the annual totals are usually associated with closed upper-level lows cut off from the westerly current moving independently of that current. Such systems leave large quantities of precipitation over a few square kilometers. Summer convection in the plains (north Meseta, south Meseta, and Ebro River valley) also results in localized precipitation. But even for stratiform precipitation, orographic factors generate an uneven distribution of precipitation over the territory. The result is a highly decorrelated precipitation field in terms of distance. The ability to successfully measure such fields is highly dependent on the proper location of rain gauges so that their measurements are representative of a large area around the station. However, this is seldom the case. The limited coverage of the first-order network makes it so that rain measurements are highly local, that is, they only represent a small area. Large decorrelations in terms of distance are observed even a few hectometers apart and even in perfectly flat terrain. For automatic stations other factors contribute to increase the uncertainty in the measurements (Cecinati et al. 2018; Molini et al. 2005; Nystuen 1999).

Indeed, point-wise estimates of precipitation derived from the IMERG do correspond with high-quality ground observations (Fig. 11). The question is what happens outside such points, where no observations are available. It should be noted that any ground-based estimate of 

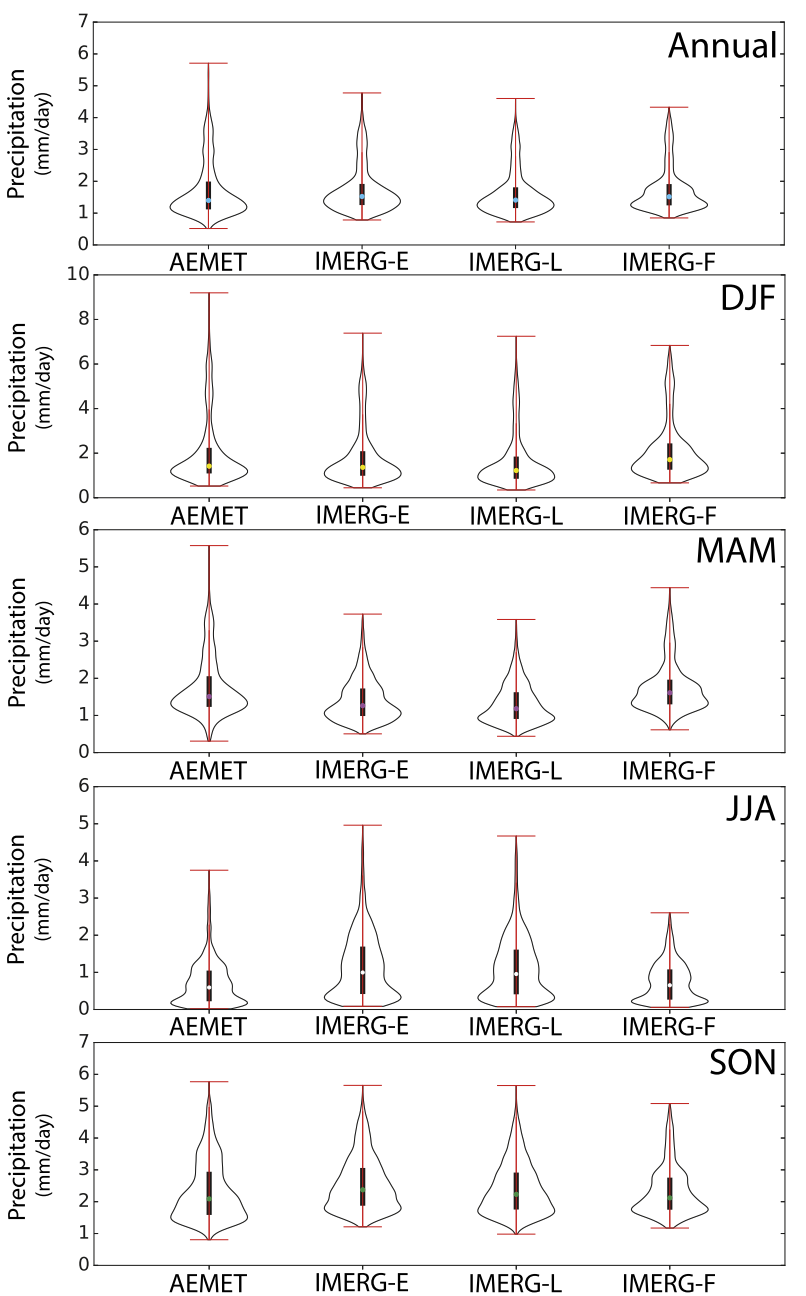

FIG. 10. Probability density functions (PDFs) of (first row) annual and (second through fifth rows) seasonal precipitation for the AEMET, IMERG-E, IMERG-L, and IMERG-F datasets.

precipitation outside the station is the results of spatial interpolation using, for instance, a kriging procedure, and that such interpolation depends on assumptions on the spatial decorrelation of precipitation. Figure 12 demonstrates that the spatial structure of the satellite-derived and the rain gauge-derived fields are quite different. That does not mean however that the satellite is wrong. On the contrary, considering the larger number of cases where the satellite compares well with an adequate number of gauges, may indicate that IMERG can be indeed be used to fill the gaps in sparse rain gauge networks.

IMERG is a global retrieval system that must perform in regions with sparse rain gauges and only monthly data availability. This leads to smoothing decisions within the algorithm that may or may not be optimal for relatively dense gauge networks such as Spain where data are also available on a daily scale. Data fusion (microwave and infrared) and a sensible combination of available information (rain gauges) on a local scale may thus yield much better results for hydrological operations. Indirect methods have proven useful when enough numbers of rain gauges are used, but it should be also borne in mind that heavily instrumented basins are uncommon. In fact, before the GPM era it was generally accepted that ground-based, in situ observations, satellite data, and regional weather modeling could not individually provide the high-quality precipitation data required for hydrological prediction, especially over complex terrain (Pan et al. 2017) where rain gauges are usually sparse and not always representative of large areas around them.

At this point one may naturally ask about the dependence of the IMERG with the number of rain gauges used through the GPCC data for its calibration. As expected, the larger the number of gauges in a GPCC $1^{\circ} \times 1^{\circ}$ grid box, the more correlated IMERG-F is with GPCC. Figure 14a quantifies such observations: in areas where no gauges are available, the mean $r^{2}$ correlation drops below 0.70. If just one rain gauge can be used, then there is clear improvement (0.80). A further increase yields dramatic improvements ( 0.85 with two gauges).

Figure 14 also provides input about which areas are the larger contributors to low performances. These instances correspond with coastal pixels. Without them, the statistics in Fig. 14a greatly improve. Since those areas are the least interesting in terms of the hydrology of the Spanish rivers (they correspond with river mouths), the potential of the IMERG to inform hydrologic operations is not affected. The same applies to other applications such as agriculture and water resources management, since the coastline is mostly devoted to tourism and there are no major dams and reservoir near the river mouths and estuaries. In the insurance realm, however, the limited skill of the IMERG in coastal areas can be an issue.

Data fusion that is more attuned to local variability of input data has long been represented in data assimilation. Reanalyses can provide a physically consistent, best-available estimate of the precipitation using all available information.

Figure 15 shows estimated precipitation from reanalysis (ERA-5), observations (AEMET), and satellite estimates (IMERG and TMPA) for two cases, 15 January 2015 and 25 February 2015 . ERA5 is artificially smooth since there is no minimum threshold for precipitation, but it correctly replicates the observations (which in this case have not been used for the reanalysis; the only potential conflict here is temporal autocorrelation). In the first case (Fig. 15a), there is a local maximum in the Central System that does not feature in IMERG-F and that appears in a slightly different position (windward to the mountain range) in the AEMET measurements. The other local maximum near Seville (about $37^{\circ} \mathrm{N}$, 

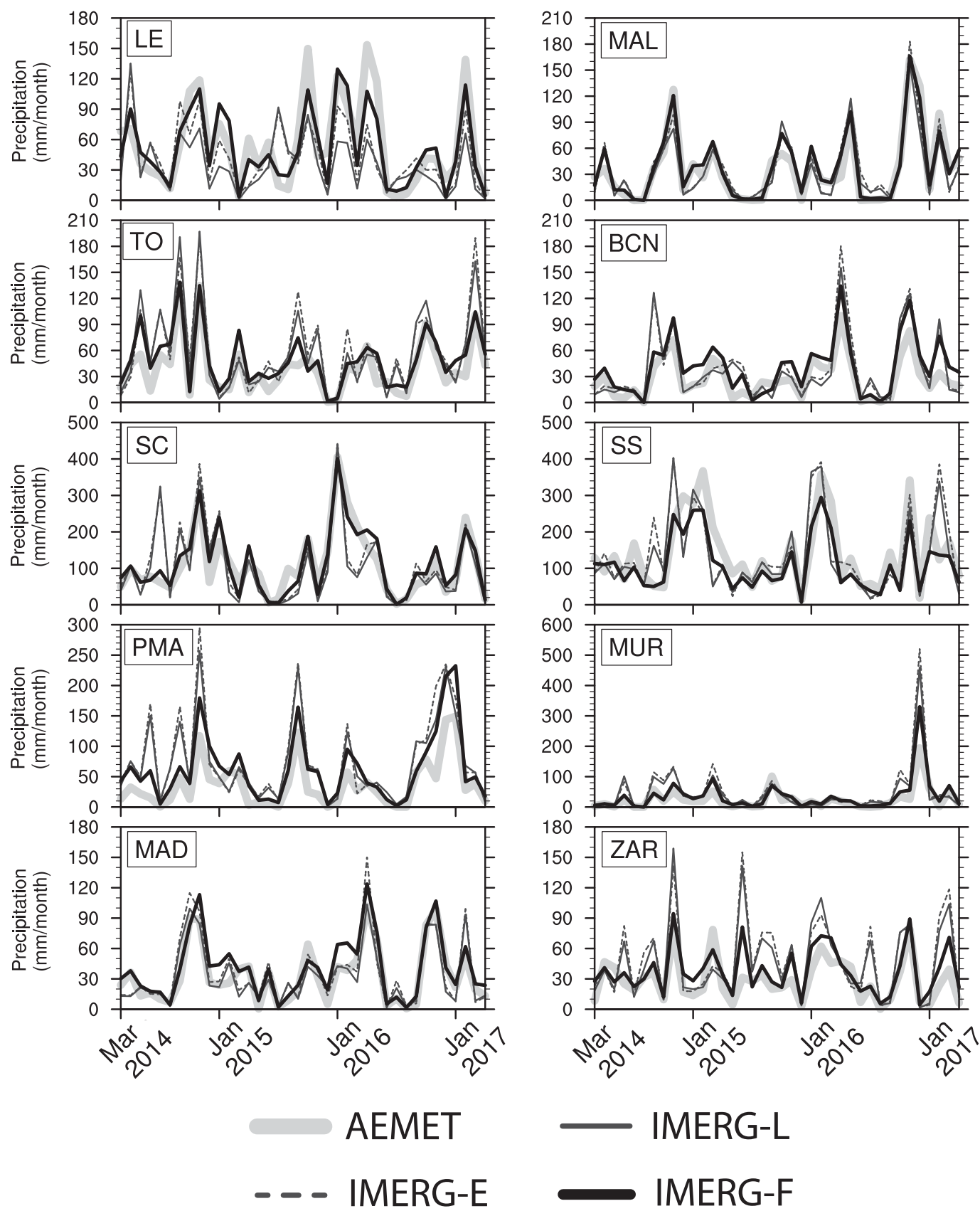

FIG. 11. Time series of monthly precipitation for 10 Spanish cities: León (LE), Málaga (MAL), Toledo (TO), Barcelona (BCN), Santiago de Compostela (SC), San Sebastián (SS), Palma de Mallorca (PMA), Murcia (MUR), Madrid (MAD), and Zaragoza (ZAR).

$5.5^{\circ} \mathrm{W}$ ) in Fig. $15 \mathrm{a}$ is missing. Similar issues arise in the TMPA estimate, which contrast with observations, reanalysis, and IMERG in both cases.

In the Central System case, there is a likely explanation that reveals an important point. Figure 13 (bottom) depicts the location of the rain gauges used to create both the AEMET estimate and to perform the gauge correction in IMERG-F. The stations are limited to low-lying areas, while the mountains are almost uninstrumented. The consequence of the almost absence of mountain stations that could be used for the calibration of the satellite precipitation algorithms is a marked underestimation of the actual rain over the higher altitudes of the country, as Fig. 15 shows: compared with ERA5, which is the reference, IMERG-F does not provide a precise picture of precipitation in the mountain areas of Spain. Even compared with 

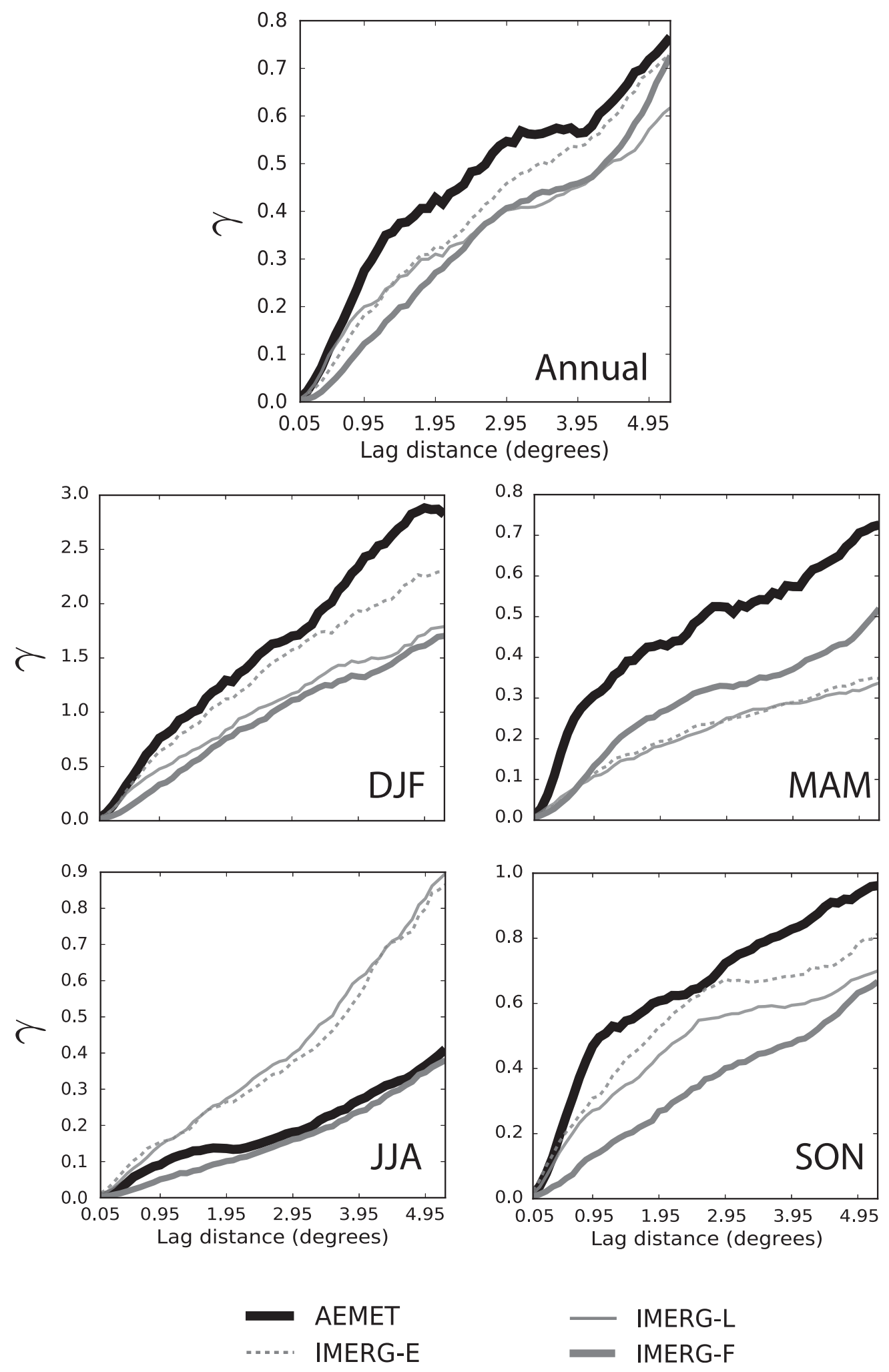

FIG. 12. Variograms of annual and seasonal precipitation for AEMET data and the three estimates of the IMERG. 


\begin{tabular}{|c|c|c|c|c|c|}
\hline$\dot{\sigma}$ & $\stackrel{\mathbb{N}}{N}$ & $\partial^{0}$ & 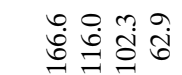 & 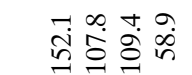 & 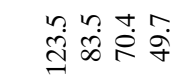 \\
\hline के & 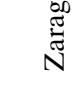 & 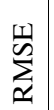 & 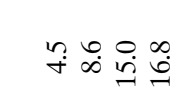 & $\stackrel{\circ}{\dot{m}} \stackrel{\infty}{\sim} \stackrel{\infty}{\dot{ \pm}} \stackrel{0}{\sim}$ & 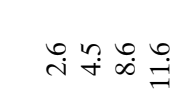 \\
\hline$\stackrel{0}{\bar{\pi}}$ & ב & $\partial^{0}$ & 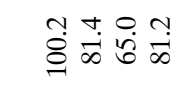 & 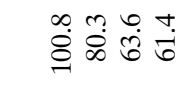 & 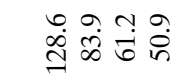 \\
\hline 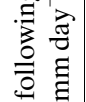 & $\sum^{\pi}$ & $\sum_{\infty}^{\infty}$ & 우 궁 & $\vec{\sim} \stackrel{\infty}{+} \mathfrak{r}$ & 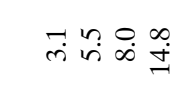 \\
\hline 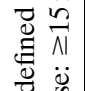 & . $\frac{\pi}{0}$ & $\partial^{0}$ & 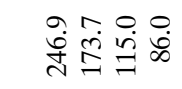 & 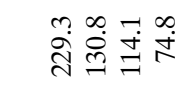 & $\begin{array}{l}\infty \\
\dot{\sigma} \sigma \\
\dot{\sigma}\end{array}$ \\
\hline 峁泀 & $\stackrel{\Xi}{\Sigma}$ & 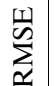 & 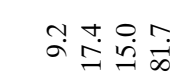 & ลำ & $\ddot{n} \bar{b} \stackrel{\circ}{\circ} \hat{y}$ \\
\hline 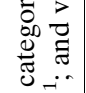 & $\underset{0}{0}$ & $\partial^{0}$ & 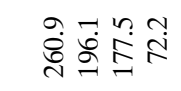 & 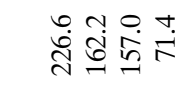 & 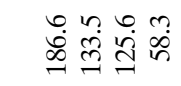 \\
\hline 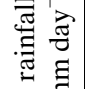 & 严 & $\sum_{\Omega}^{\infty}$ & 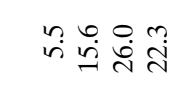 & 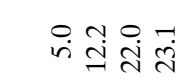 & 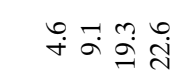 \\
\hline 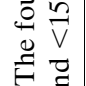 & 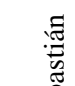 & $\alpha^{\circ}$ & 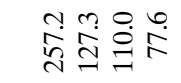 & 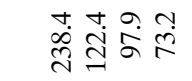 & 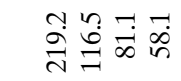 \\
\hline$\stackrel{0}{\tilde{Z}} \overrightarrow{0}$ & $\begin{array}{l}\infty \\
\tilde{N} \\
\tilde{N}\end{array}$ & 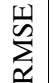 & 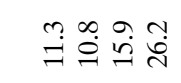 & 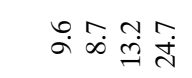 & 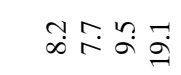 \\
\hline 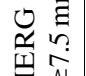 & 80 & $\partial^{\circ}$ & س & 光象 & 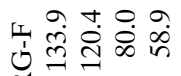 \\
\hline 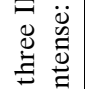 & 芯 & 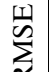 & 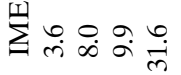 & 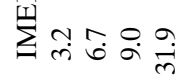 & 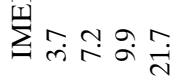 \\
\hline $\overrightarrow{\tilde{J}}$ & $\stackrel{\widetilde{0}}{\tilde{0}}$ & $\partial^{\circ}$ & 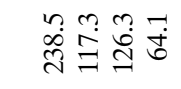 & 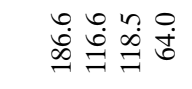 & 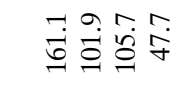 \\
\hline$\frac{n}{n}$ & صై & $\sum_{\Omega}^{\infty}$ & 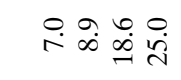 & 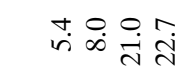 & 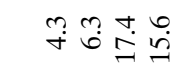 \\
\hline 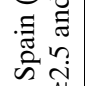 & 욤 & $\partial^{\circ}$ & ஸீ: & 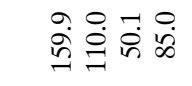 & 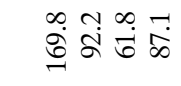 \\
\hline$\stackrel{\ddot{v}}{\tilde{v}}$ & $\overline{0}$ & 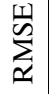 & 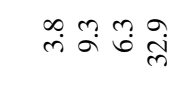 & 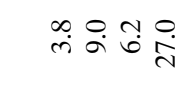 & 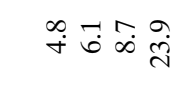 \\
\hline$\varepsilon$ & శ్ & $\partial^{\circ}$ & 흫 & 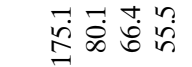 & 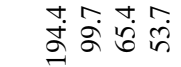 \\
\hline 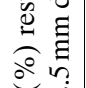 & $\sum^{\pi}$ & 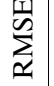 & ले Nin & 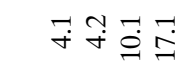 & $\stackrel{\sim}{+} \stackrel{\leftrightarrow}{\rightarrow} \stackrel{\infty}{\sigma} \underset{\sim}{+}$ \\
\hline V & & $\partial^{\circ}$ & 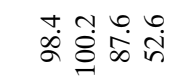 & 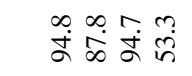 & 국ㅎํ \\
\hline 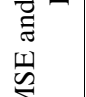 & $\stackrel{0}{\leftrightharpoons}$ & $\sum_{\substack{\infty\\
}}^{\infty}$ & $\overrightarrow{\text { 구 }}$ & 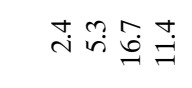 & $m \ddot{n}=\ddot{n}$ \\
\hline b & & & 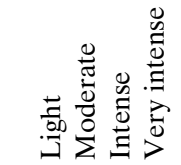 & 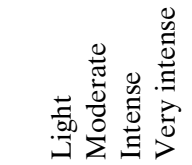 & 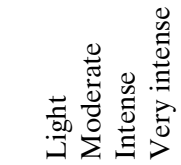 \\
\hline
\end{tabular}




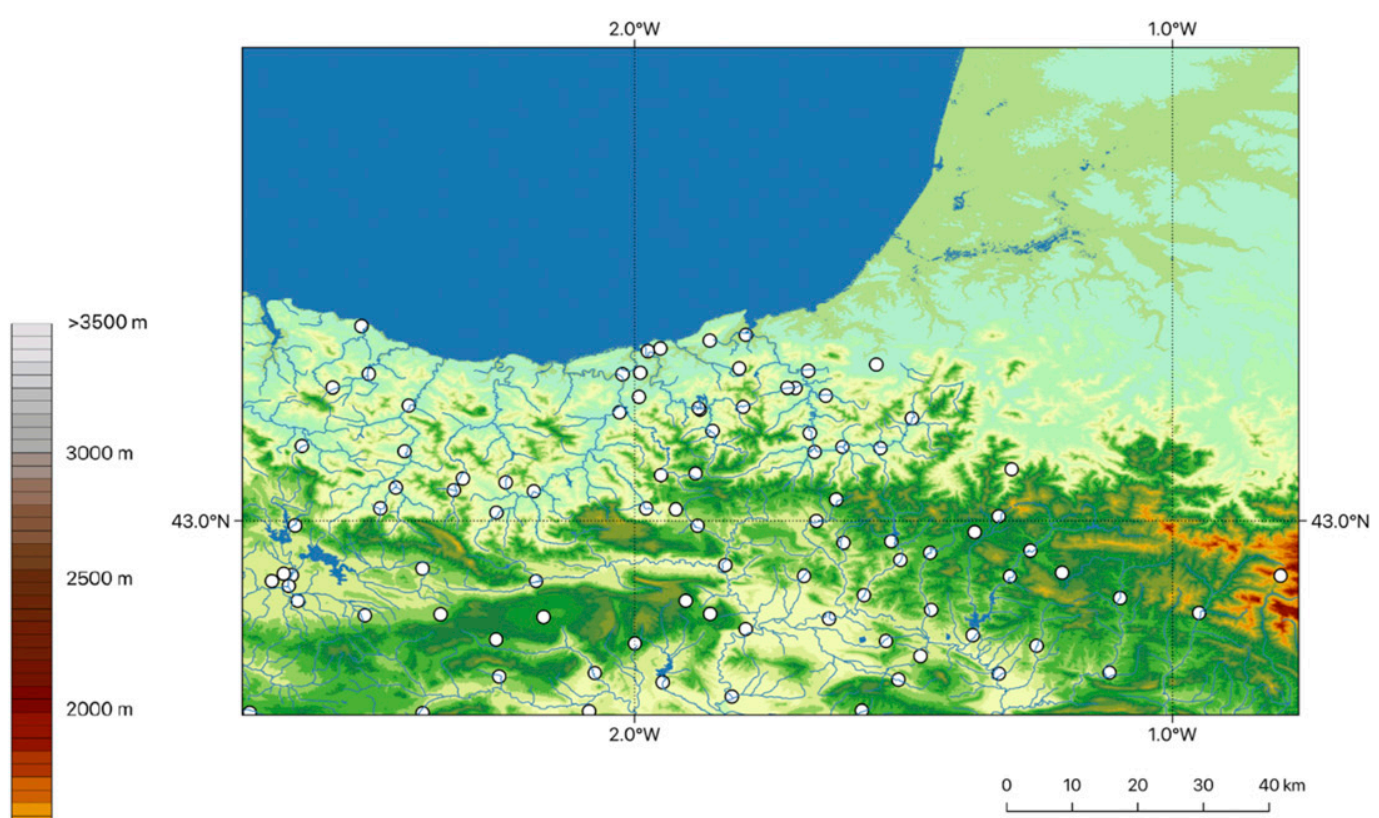

$1500 \mathrm{~m}$

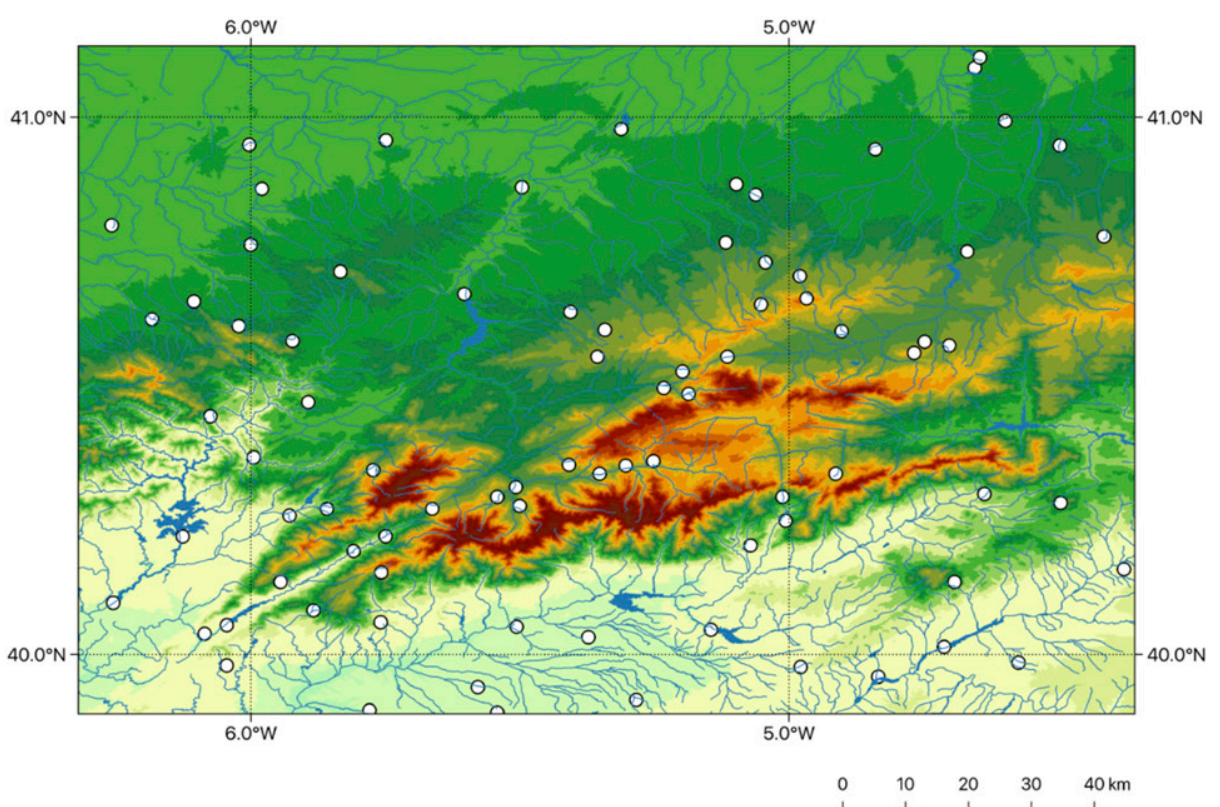

FIG. 13. (top) Topographical maps of the Bay of Biscay and the Pyrenees and (bottom) the Central System including the spatial distribution of the rain gauges for those areas.

the rain gauges-only product (AEMET's), the IMERG-F underestimates precipitation there. This is apparent in the Pyrenees where IMERG-F misses the maximum and incorrectly estimates precipitation in the northwest $\left(42.9^{\circ} \mathrm{N}\right.$, $4.8^{\circ} \mathrm{W}$, Fig. $\left.15 \mathrm{~b}\right)$. The coverage of the stations in such a large area is low (Fig. 13, top), with large high-mountain sectors with little or no information.

The issues in the Pyrenees are also apparent in the 25 February 2015 case (Fig. 15b). ERA-5 suggests far more rain in the east than the AEMET data, while IMERG-F misses much of the rain in what in reality certainly is a continuous band of precipitation stretching from the west to the east along the range. The same applies to TMPA. The misses seem to correspond with poorly instrumented areas. Moreover, the IMERG-F estimates a local maximum at $43^{\circ} \mathrm{N}, 5^{\circ} \mathrm{W}$, which is not seen in either AEMET or ERA5. Since such isolated peak cannot be the consequence of an interpolation effect, it reveals a point 


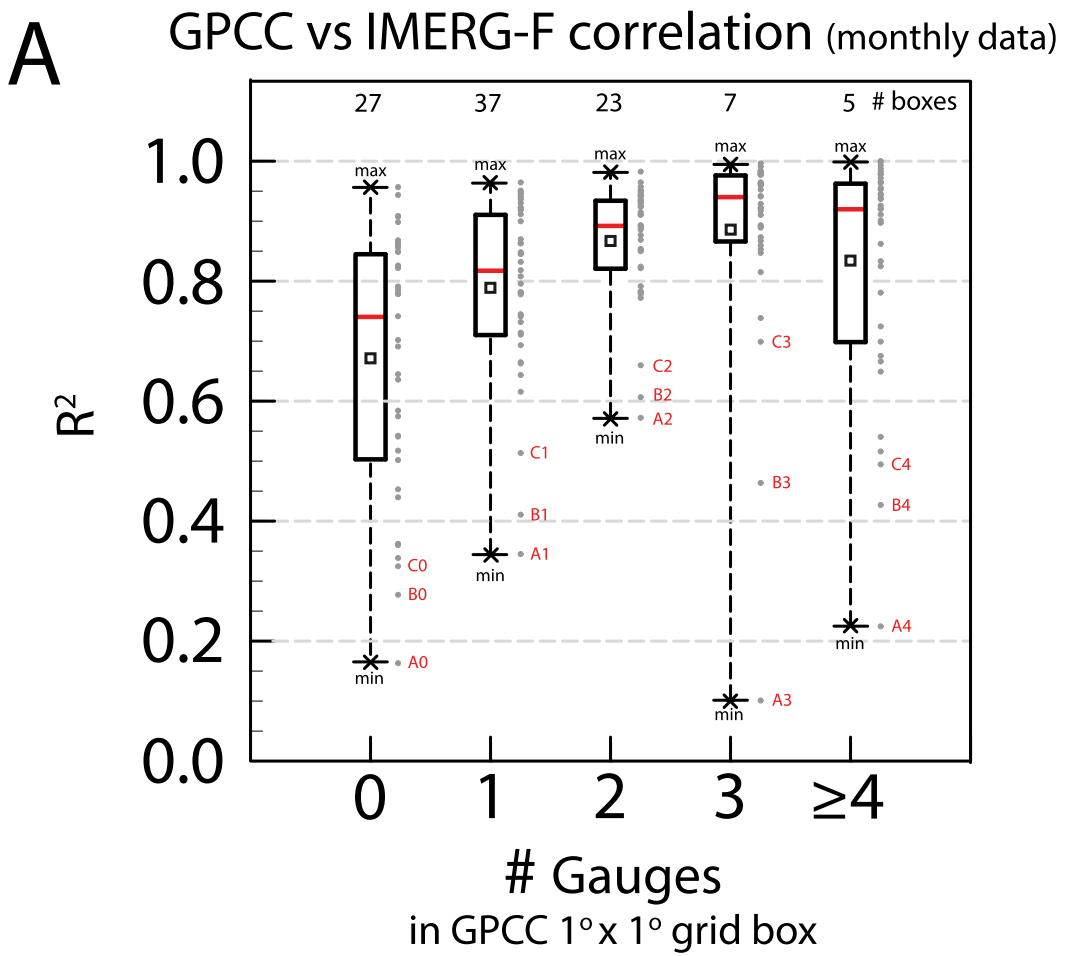

B

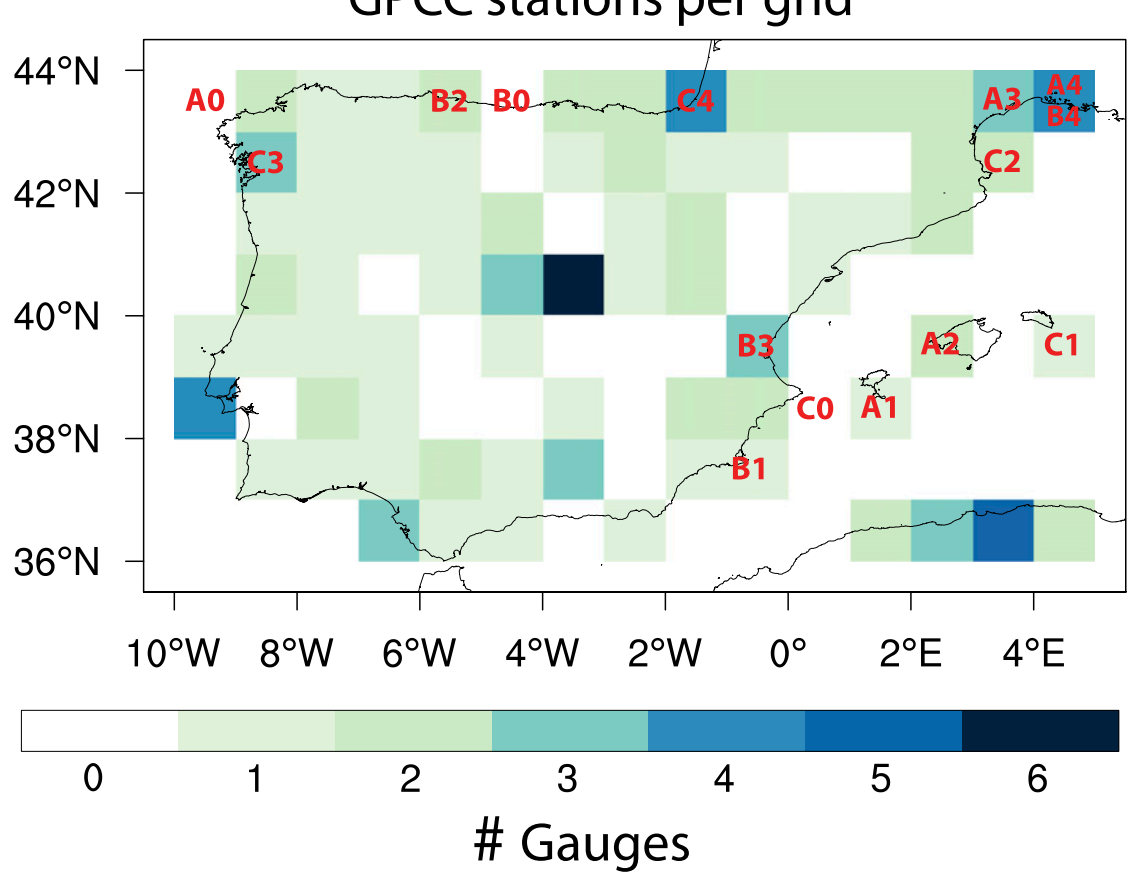

FIG. 14. (a) Boxplots of the correlation between GPCC and IMERG-F monthly data (March 2014-May 2017) estimates in each grid box, ordered according to the number of rain gauges in each box. (b) Map depicting the number of GPCC meteorological stations in each grid box and the location of those boxes for which the IMERG presents a poor correlation [cf. (a)]. 
A
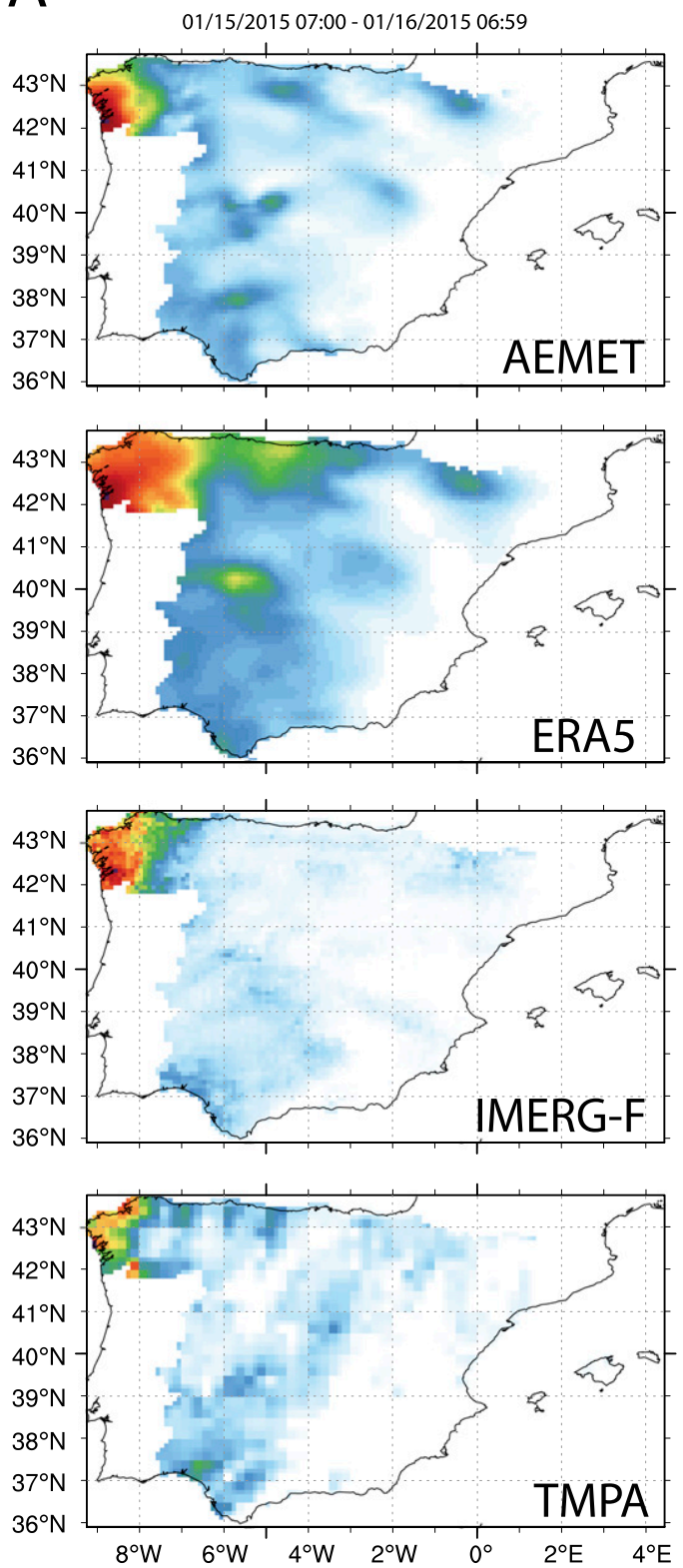

510152025303540455055 $\mathrm{mm} /$ day
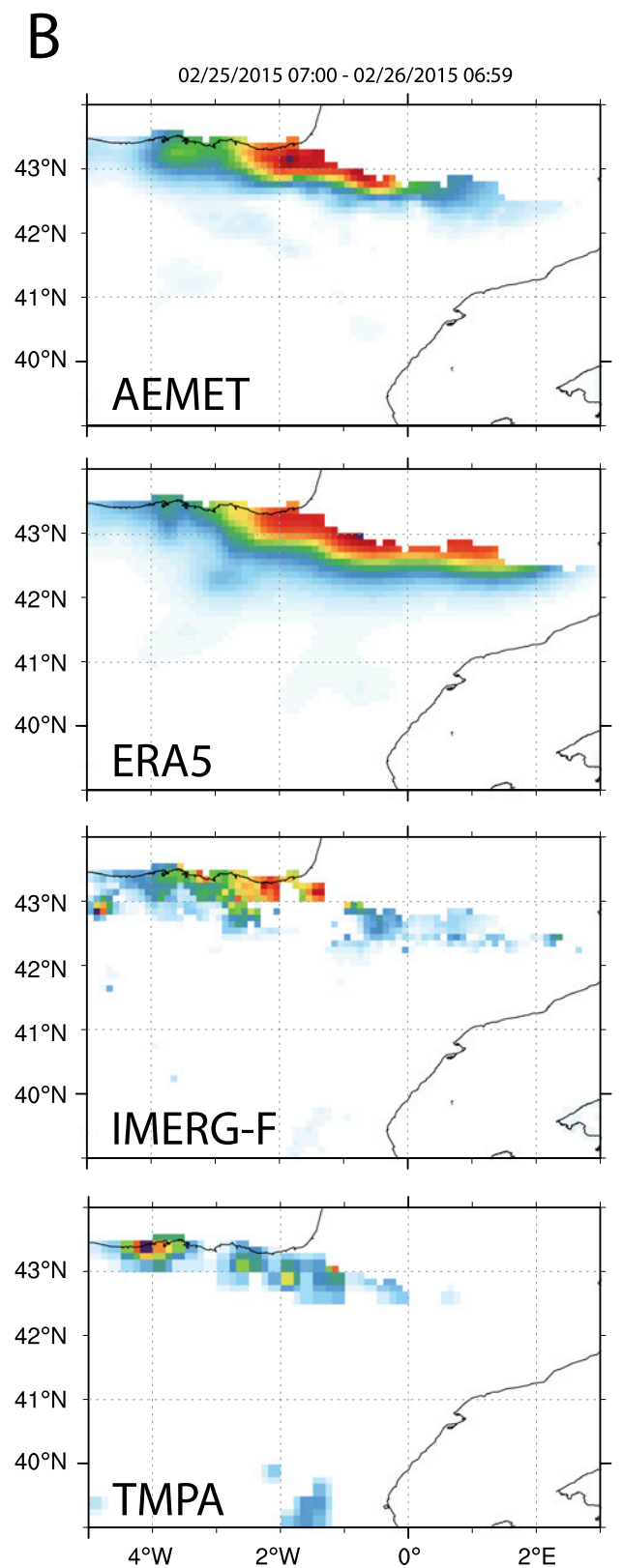

31017243138455259667380 $\mathrm{mm} /$ day

FIG. 15. A comparison of daily precipitation for two cases (a) 15 Jan 2015 and (b) 25 Feb 2015 and for four datasets: AEMET, ERA5, IMERG-F, and TMPA.

deserving attention from algorithm developers, which indeed is a major drive of these validation exercises.

If IMERG is biased toward lower precipitation consistent with the rain gauge locations, a natural question is whether or not observations or reanalyses should be used for estimates in mountainous terrain. In the case of
Spain, where much data exist to initialize the models, ERA5 is clearly the most consistent source of data in terms of corresponding with our present knowledge of the climatology of the country. Indeed, mountain areas seem to receive far more rain than those estimated by IMERG (Fig. 16). Biogeographical knowledge confirms 


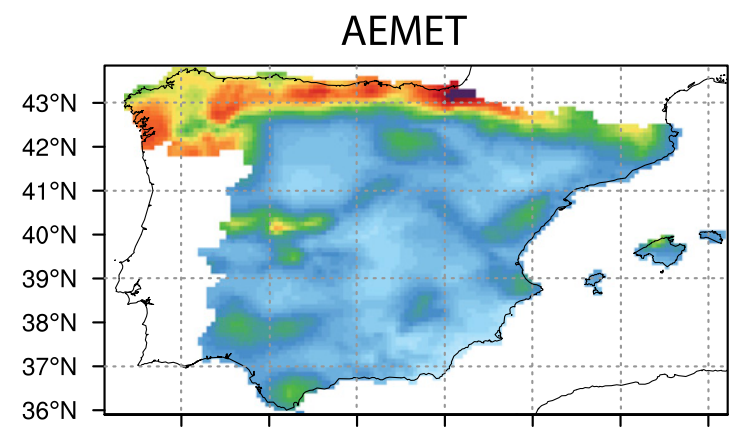

ERA5

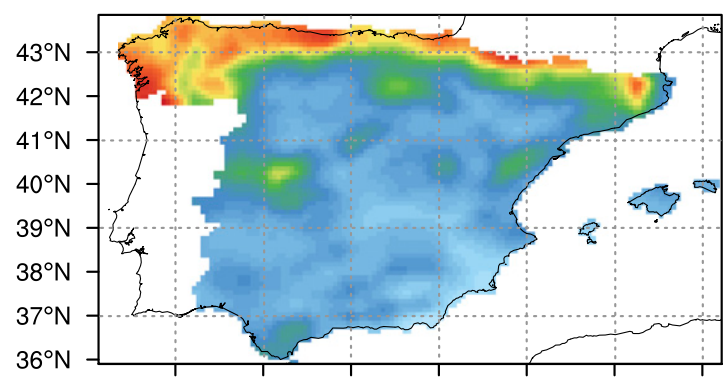

IMERG-F

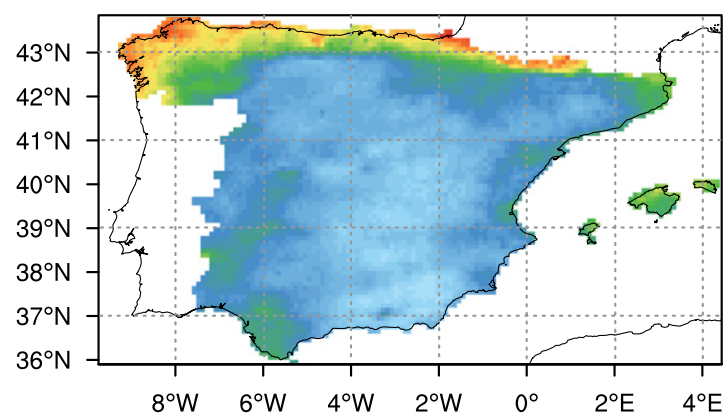

\subsection{1 .522 .533 .544 .55 $\mathrm{mm} /$ day}

FIG. 16. Annual mean precipitation for AEMET, ERA5, and IMERG-F for the March 2014-May 2017 period.

such observation: some tree species could simply not develop with the amounts of precipitation dictated by IMERG over the Spanish mountains but could do with ERA5 estimates.

Reanalysis, however, also has issues in areas where meteorological forcing data are not dense. Just as IMERG products appear to improve with rain gauge density, so ERA5 improves with meteorological forcing data. A fairly obvious role for localized data fusion thus appears. As more data are made available to schemes such as IMERG, their ability to interpolate significantly improves, while high-quality models such as ERA5 or similar weather forecast models, with all the physics imbedded in the model, are able to guide the interpolation in a physically consistent manner in orography or other data-sparse regions. Thus, while far from perfect, the apparent flaws in IMERG seen in this study appear to be issues that can be overcome by simply using more of the available data and more physical modeling in orographic terrain.

\section{Conclusions}

This paper shows that the IMERG final run, level 3 product (IMERG-F) compares the best with independent observations, which is not surprising as the gauges used for the calibration certainly help, but even the late run IMERG-L, with only a climatological adjustment to rain gauges, presents good performances. The IMERG-E early run, while featuring decreasing performance, still keeps a low bias, making it a privileged product for nearreal-time applications such as hydropower operations, water management, agriculture, and other human uses.

When there are sufficient gauges in the GPCC analysis, the IMERG final run product can be seen to reproduce the GPCC gauges quite well at the $1^{\circ}$ resolution (Fig. 3). IMERG, however, is able to describe local rainfall patterns in much greater detail due to the satellite data with $30-\mathrm{min}, 10-\mathrm{km}$ resolution. The performance and stability of IMERG is quite high despite the limited gauge data it has access to. The only noticeable shortcoming appears to be orographic enhancement (e.g., Sierra de Gredos) that GPCC does not capture and IMERG therefore also misses. This makes IMERG a reliable complement to the official AEMET rain gauge network, with the added advantage of low latency and higher spatial resolution over areas with poor gauge coverage. Despite the short period used, the 3-yr IMERG climatology already represents correctly the standard 30-yr long climatologies of precipitation of the country in spite of 2015/16 being a strong El Niño episode.

None of the datasets in this study are perfect. AEMET data must interpolate over significant distances in some regions and relies on quality control procedures that have little other data to compare to. GPCC uses only the highest quality rain gauges but misses some orographic rain features, and must interpolate over larger distances because of that. TMPA is discontinued. IMERG is an indirect measure while ERA is a model that appears to do well with orographic precipitation but has problems with the exact location of storm systems, particularly during summer convective periods. Nonetheless, it appears that the stability of IMERG would allow it to be merged with higher-resolution rain gauge data from AEMET, as well as with some of the physics related to orographic precipitation from ERA5 to produce a monitoring product 
over Spain that could be superior to any individual product currently available.

Acknowledgments. Funding from projects CGL201348367-P, CGL2016-78702-C2-1-R, CGL2016-80609-R (Ministerio de Economía y Competitividad), UNCM081E-086 (Ministerio de Ciencia e Innovación), and Development of Numerical Weather Prediction and Data Application Technique 1365002970/KMA201800721 (Korea Meteorological Administration) is gratefully acknowledged. AN, EGO, AM, and JLS acknowledge grant LE240P18. FJT also acknowledges the Joint Research Proposal for Precipitation Research in Spain within NASA's Precipitation Measurement Missions (PMM) Research Program and discussions with other members of the PMM science and international teams.

\section{REFERENCES}

Adler, R., and Coauthors, 2018: The Global Precipitation Climatology Project (GPCP) monthly analysis (new version 2.3) and a review of 2017 global precipitation. Atmosphere, 9, 138, https://doi.org/ 10.3390/atmos9040138.

Brunetti, M. T., M. Melillo, S. Peruccacci, L. Ciabatta, and L. Brocca, 2018: How far are we from the use of satellite rainfall products in landslide forecasting? Remote Sens. Environ., 210, 65-75, https://doi.org/10.1016/j.rse.2018.03.016.

Cecinati, F., A. M. Moreno-Ródenas, M. A. Rico-Ramirez, M.-C. ten Veldhuis, and J. G. Langeveld, 2018: Considering rain gauge uncertainty using kriging for uncertain data. Atmosphere, 9, 446, https://doi.org/10.3390/atmos9110446.

Currier, W. R., T. Thorson, and J. D. Lundquist, 2017: Independent evaluation of frozen precipitation from WRF and PRISM in the Olympic Mountains. J. Hydrometeor., 18, 2681-2703, https://doi.org/10.1175/JHM-D-17-0026.1.

Gabella, M., P. Speirs, U. Hamann, U. Germann, and A. Berne, 2017: Measurement of precipitation in the Alps using dualpolarization C-band ground-based radars, the GPM spaceborne Ku-band radar, and rain gauges. Remote Sens., 9, 1147, https://doi.org/10.3390/rs9111147.

Gallego, M. C., J. A. García, J. M. Vaquero, and V. L. Mateos, 2006: Changes in frequency and intensity of daily precipitation over the Iberian Peninsula. J. Geophys. Res., 111, D24105, https://doi.org/10.1029/2006JD007280.

Gandin, L. S., 1965: Objective Analysis of Meteorological Fields. Israel Program for Scientific Translations, $242 \mathrm{pp}$.

García-Ortega, E., J. Lorenzana, A. Merino, S. FernándezGonzález, L. López, and J. L. Sánchez, 2017: Performance of multiphysics ensembles in convective precipitation events over northeastern Spain. Atmos. Res., 190, 55-67, https://doi.org/10.1016/j.atmosres.2017.02.009.

Germann, U., and J. Joss, 2001: Variograms of radar reflectivity to describe the spatial continuity of Alpine precipitation. J. Appl. Meteor., 40, 1042-1059, https://doi.org/10.1175/1520-0450(2001) $040<1042$ :VORRTD $>2.0$. CO;2.

Gutiérrez, J. M., and F. Aguado, 2006: Quality image for the Spanish National Radar Composition. Proc. Fourth European Conf. on Radar in Meteorology and Hydrology, Barcelona, Spain, Instituto Nacional de Meteorología, $23 \mathrm{pp}$.
Habib, E. H., A. Meselhe Ehab, and V. Aduvala Ananda, 2008: Effect of local errors of tipping-bucket rain gauges on rainfallrunoff simulations. J. Hydrol. Eng., 13, 488-496, https:// doi.org/10.1061/(ASCE)1084-0699(2008)13:6(488).

Hersbach, H., and Coauthors, 2019: Global reanalysis: Goodbye ERA-Interim, hello ERA5. ECMWF Newsletter, No. 159, ECMWF, Reading, United Kingdom, 17-24, https:// www.ecmwf.int/node/19027.

Hou, A. Y., and Coauthors, 2014: The Global Precipitation Measurement mission. Bull. Amer. Meteor. Soc., 95, 701-722, https://doi.org/10.1175/BAMS-D-13-00164.1.

Hourdin, F., and Coauthors, 2017: The art and science of climate model tuning. Bull. Amer. Meteor. Soc., 98, 589-602, https:// doi.org/10.1175/BAMS-D-15-00135.1.

Huffman, G. J., R. F. Adler, M. M. Morrissey, D. T. Bolvin, S. Curtis, R. Joyce, B. McGavock, and J. Susskind, 2001: Global precipitation at one-degree daily resolution from multisatellite observations. J. Hydrometeor, 2, 36-50, https://doi.org/ 10.1175/1525-7541(2001)002<0036:GPAODD > 2.0.CO;2.

_ , and Coauthors, 2007: The TRMM Multisatellite Precipitation Analysis (TMPA): Quasi-global, multiyear, combined-sensor precipitation estimates at fine scales. J. Hydrometeor., 8, 38-55, https://doi.org/10.1175/JHM560.1.

- - , and Coauthors, 2018: NASA Global Precipitation Measurement (GPM) Integrated Multi-satellitE Retrievals for GPM (IMERG). Algorithm Theoretical Basis Doc., version 5.2, 35 pp., https://pmm.nasa.gov/sites/default/files/document_files/ IMERG_ATBD_V5.2_0.pdf.

$\longrightarrow$, D. T. Bolvin, E. J. Nelkin, and J. Tan, 2019: Integrated MultisatellitE Retrievals for GPM (IMERG) technical documentation. Tech. Doc., 77 pp., https://pmm.nasa.gov/sites/default/ files/document_files/IMERG_doc_190909.pdf.

Jones, P. W., 1999: First- and second-order conservative remapping schemes for grids in spherical coordinates. Mon. Wea. Rev., 127, 2204-2210, https://doi.org/10.1175/1520-0493(1999)127<2204: FASOCR $>2.0 . \mathrm{CO} ; 2$.

Kidd, C., and Coauthors, 2017: So, how much of the earth's surface is covered by rain gauges? Bull. Amer. Meteor. Soc., 98, 69-78, https://doi.org/10.1175/BAMS-D-14-00283.1.

Köppen, W., 1900: Versuch einer klassifikation der klimate, vorzugsweise nach ihren beziehungen zur pflanzenwelt. Geogr. Z., 6, 657-679.

Maggioni, V., H. J. Vergara, E. N. Anagnostou, J. J. Gourley, Y. Hong, and D. Stampoulis, 2013: Investigating the applicability of error correction ensembles of satellite rainfall products in river flow simulations. J. Hydrometeor., 14, 1194-1211, https://doi.org/10.1175/JHM-D-12-074.1.

Manz, B., S. Páez-Bimos, N. Horna, W. Buytaert, B. Ochoa-Tocachi, W. Lavado-Casimiro, and B. Willems, 2017: Comparative ground validation of IMERG and TMPA at variable spatiotemporal scales in the tropical Andes. J. Hydrometeor., 18, 2469-2489, https://doi.org/10.1175/JHM-D-16-0277.1.

Marcos, C., J. M. Sancho, and F. J. Tapiador, 2015: NWC SAF convective precipitation product from MSG: A new day-time method based on cloud top physical properties. Tethys J. Wea. Climate West. Mediterr., 2015, 3-11, https://doi.org/10.3369/TETHYS.2015.12.01.

Merino, A., E. García-Ortega, L. López, J. L. Sánchez, and A. M. Guerrero-Higueras, 2013: Synoptic environment, mesoscale configurations and forecast parameters for hailstorms in Southwestern Europe. Atmos. Res., 122, 183-198, https:// doi.org/10.1016/j.atmosres.2012.10.021.

Molini, A., L. G. Lanza, and P. L. Barbera, 2005: The impact of tipping-bucket raingauge measurement errors on design rainfall 
for urban-scale applications. Hydrol. Processes, 19, 1073-1088, https://doi.org/10.1002/hyp.5646.

Nešpor, V., and B. Sevruk, 1999: Estimation of wind-induced error of rainfall gauge measurements using a numerical simulation. J. Atmos. Oceanic Technol., 16, 450-464, https://doi.org/ 10.1175/1520-0426(1999)016<0450:EOWIEO > 2.0.CO;2.

Nystuen, J. A., 1999: Relative performance of automatic rain gauges under different rainfall conditions. J. Atmos. Oceanic Technol., 16, 1025-1043, https://doi.org/10.1175/1520-0426(1999) 016<1025:RPOARG $>2.0 . \mathrm{CO} ; 2$.

Oliveira, R., V. Maggioni, D. Vila, and L. Porcacchia, 2018: Using satellite error modeling to improve GPM-level 3 rainfall estimates over the central Amazon region. Remote Sens., 10, 336, https://doi.org/10.3390/rs10020336.

Pan, X., X. Li, G. Cheng, and Y. Hong, 2017: Effects of 4D-Var data assimilation using remote sensing precipitation products in a WRF model over the complex terrain of an arid region river basin. Remote Sens., 9, 963, https://doi.org/10.3390/rs9090963.

Peral, C., B. Navascués, and P. Ramos, 2017: Serie de precipitación diaria en rejilla con fines climáticos. AEMET Tech. Note 24,30 pp., https://www.aemet.es/documentos/es/conocermas/ recursos_en_linea/publicaciones_y_estudios/publicaciones/ NT_24_AEMET/NT_24_AEMET.pdf.

Petracca, M., L. P. D'Adderio, F. Porcù, G. Vulpiani, S. Sebastianelli, and S. Puca, 2018: Validation of GPM dual-frequency precipitation radar (DPR) rainfall products over Italy. J. Hydrometeor., 19, 907-925, https://doi.org/10.1175/JHM-D-17-0144.1.

Retalis, A., D. Katsanos, F. Tymvios, and S. Michaelides, 2018: Validation of the first years of GPM operation over Cyprus. Remote Sens., 10, 1520, https://doi.org/10.3390/RS10101520.

Schneider, U., P. Finger, A. Meyer-Christoffer, E. Rustemeier, M. Ziese, and A. Becker, 2017: Evaluating the hydrological cycle over land using the newly-corrected precipitation climatology from the Global Precipitation Climatology Centre (GPCC). Atmosphere, 8, 52, https://doi.org/10.3390/atmos8030052.

- A. Becker, P. Finger, A. Meyer-Christoffer, M. Ziese, 2018: GPCC monitoring product: Near real-time monthly land-surface precipitation from rain-gauges based on SYNOP and CLIMAT data. GPCC, accessed 4 April 2019, http://doi.org/10.5676/ DWD_GPCC/MP_M_V6_100.

Skofronick-Jackson, G., and Coauthors, 2017a: The Global Precipitation Measurement (GPM) mission for science and society. Bull. Amer. Meteor. Soc., 98, 1679-1695, https://doi.org/ 10.1175/BAMS-D-15-00306.1.

_ G. Huffman, and W. Petersen, 2017b: Three years of the Global Precipitation Measurement (GPM) mission. 2017 IEEE Int. Geoscience and Remote Sensing Symp., Fort Worth, TX, IEEE, 2704-2707, https://doi.org/10.1109/IGARSS.2017.8127554.

, D. Kirschbaum, W. Petersen, G. Huffman, C. Kidd, E. Stocker, and R. Kakar, 2018a: The Global Precipitation
Measurement (GPM) mission's scientific achievements and societal contributions: Reviewing four years of advanced rain and snow observations. Quart. J. Roy. Meteor. Soc., 144, 27-48, https://doi.org/10.1002/qj.3313.

_, S. J. Munchak, M. Kulie, L. Milani, N. Wood, and G. Huffman, 2018b: The Global Precipitation Measurement (GPM) mission status: Emphasis on falling snow retrievals. 2018 IEEE Int. Geoscience and Remote Sensing Symp., Valencia, Spain, IEEE 8316-8319, https://doi.org/10.1109/IGARSS.2018.8519544.

Sungmin, O., U. Foelsche, G. Kirchengast, J. Fuchsberger, J. Tan, and W. A. Petersen, 2017: Evaluation of GPM IMERG early, late, and final rainfall estimates using WegenerNet gauge data in southeastern Austria. Hydrol. Earth Syst. Sci., 21, 65596572, https://doi.org/10.5194/hess-21-6559-2017.

Tan, J., W. A. Petersen, and A. Tokay, 2016: A novel approach to identify sources of errors in IMERG for GPM ground validation. J. Hydrometeor., 17, 2477-2491, https://doi.org/10.1175/ JHM-D-16-0079.1.

Tapiador, F. J., 2019: The Geography of Spain. Springer, 480 pp.

- A. Behrangi, Z. S. Haddad, D. Katsanos, and M. De Castro, 2016: Disruptions in precipitation cycles: Attribution to anthropogenic forcing. J. Geophys. Res. Atmos., 121, 2161-2177, https://doi.org/10.1002/2015JD023406.

__ and Coauthors, 2017: Global precipitation measurements for validating climate models. Atmos. Res., 197, 1-20, https:// doi.org/10.1016/j.atmosres.2017.06.021.

Tian, F., S. Hou, L. Yang, H. Hu, and A. Hou, 2018: How does the evaluation of the GPM IMERG rainfall product depend on gauge density and rainfall intensity? J. Hydrometeor., 19, 339349, https://doi.org/10.1175/JHM-D-17-0161.1.

Tian, Y., C. D. Peters-Lidard, B. J. Choudhury, and M. Garcia, 2007: Multitemporal analysis of TRMM-based satellite precipitation products for land data assimilation applications. J. Hydrometeor., 8, 1165-1183, https://doi.org/10.1175/2007JHM859.1.

UNCCD, 2017: Sustainable land management contribution to successful land-based climate change adaptation and mitigation. United Nations Convention to Combat Desertification, 178 pp., http://www.indiaenvironmentportal.org.in/files/file/ UNCCD_Report_SLM.pdf.

Upton, G. J. G., and A. R. Rahimi, 2003: On-line detection of errors in tipping-bucket raingauges. J. Hydrol., 278, 197-212, https://doi.org/10.1016/S0022-1694(03)00142-2.

Villarini, G., P. V. Mandapaka, W. F. Krajewski, and R. J. Moore, 2008: Rainfall and sampling uncertainties: A rain gauge perspective. J. Geophys. Res., 113, D11102, https://doi.org/10.1029/ 2007JD009214.

Watters, D., A. Battaglia, K. Mroz, and F. Tridon, 2018: Validation of the GPM version-5 surface rainfall products over Great Britain and Ireland. J. Hydrometeor., 19, 1617-1636, https:// doi.org/10.1175/JHM-D-18-0051.1. 